Atmos. Chem. Phys., 13, 12507-12524, 2013

www.atmos-chem-phys.net/13/12507/2013/

doi:10.5194/acp-13-12507-2013

(c) Author(s) 2013. CC Attribution 3.0 License.

\title{
Model for acid-base chemistry in nanoparticle growth (MABNAG)
}

\author{
T. Yli-Juuti ${ }^{1}$, K. Barsanti ${ }^{2}$, L. Hildebrandt Ruiz ${ }^{3},{ }^{*}$, A.-J. Kieloaho ${ }^{1}$, U. Makkonen ${ }^{4}$, T. Petäjä ${ }^{1}$, T. Ruuskanen ${ }^{1}$, \\ M. Kulmala ${ }^{1}$, and I. Riipinen ${ }^{5}$ \\ ${ }^{1}$ Department of Physics, University of Helsinki, Helsinki, Finland \\ ${ }^{2}$ Department of Civil and Environmental Engineering, Portland State University, Portland, OR, USA \\ ${ }^{3}$ Atmospheric Chemistry Division, National Center for Atmospheric Research, Boulder, CO, USA \\ ${ }^{4}$ Finnish Meteorological Institute, Helsinki, Finland \\ ${ }^{5}$ Department of Applied Environmental Science and Bert Bolin Centre for Climate Research, Stockholm University, \\ Stockholm, Sweden \\ *now at: McKetta Department of Chemical Engineering, The University of Texas at Austin, Austin, TX, USA
}

Correspondence to: T. Yli-Juuti (taina.yli-juuti@helsinki.fi)

Received: 11 February 2013 - Published in Atmos. Chem. Phys. Discuss.: 18 March 2013

Revised: 22 November 2013 - Accepted: 25 November 2013 - Published: 20 December 2013

\begin{abstract}
Climatic effects of newly-formed atmospheric secondary aerosol particles are to a large extent determined by their condensational growth rates. However, all the vapours condensing on atmospheric nanoparticles and growing them to climatically relevant sizes are not identified yet and the effects of particle phase processes on particle growth rates are poorly known. Besides sulfuric acid, organic compounds are known to contribute significantly to atmospheric nanoparticle growth. In this study a particle growth model MABNAG (Model for Acid-Base chemistry in NAnoparticle Growth) was developed to study the effect of salt formation on nanoparticle growth, which has been proposed as a potential mechanism lowering the equilibrium vapour pressures of organic compounds through dissociation in the particle phase and thus preventing their evaporation. MABNAG is a model for monodisperse aqueous particles and it couples dynamics of condensation to particle phase chemistry. Non-zero equilibrium vapour pressures, with both size and composition dependence, are considered for condensation. The model was applied for atmospherically relevant systems with sulfuric acid, one organic acid, ammonia, one amine and water in the gas phase allowed to condense on 3-20 nm particles. The effect of dissociation of the organic acid was found to be small under ambient conditions typical for a boreal forest site, but considerable for base-rich environments (gas phase concentrations of about $10^{10} \mathrm{~cm}^{-3}$ for the sum of the bases). The contribution of the bases to particle mass decreased as particle size increased, except at very high gas phase concentra-
\end{abstract}

tions of the bases. The relative importance of amine versus ammonia did not change significantly as a function of particle size. While our results give a reasonable first estimate on the maximum contribution of salt formation to nanoparticle growth, further studies on, e.g. the thermodynamic properties of the atmospheric organics, concentrations of low-volatility organics and amines, along with studies investigating the applicability of thermodynamics for the smallest nanoparticles are needed to truly understand the acid-base chemistry of atmospheric nanoparticles.

\section{Introduction}

Atmospheric aerosol particles affect the climate by scattering solar radiation and by acting as cloud condensation nuclei $(\mathrm{CCN})$. Both of these aerosol climate effects depend on particle size. A significant fraction of atmospheric aerosol particles may be formed by nucleation (Merikanto et al., 2009), but these nanometre sized particles need to grow tens of nanometres to effectively act as climate forcers. During their growth, a fraction of the nanoparticles are lost due to coagulation to larger particles, and the survival probability to $\mathrm{CCN}$ sizes depends on how fast the particles grow relative to their coagulation rate (Kerminen et al., 2004; Pierce and Adams, 2007). Therefore, correctly accounting for the nanoparticle growth is crucial for correct representation of aerosol effects in climate models (Riipinen et al., 2011). This requires

Published by Copernicus Publications on behalf of the European Geosciences Union. 
knowledge of the vapours condensing on the nanoparticles and the processes related to the nanoparticle growth.

The chemical composition of atmospheric nanoparticles and vapours condensing on them are not fully resolved yet. Several studies indicate that the key compound in atmospheric nucleation is sulfuric acid (Weber et al., 1995; Kulmala et al., 2006; Kuang et al., 2008; Sipilä et al., 2010), likely assisted by basic compounds (Kurtén et al., 2008; Ortega et al., 2008; Berndt et al., 2010; Kirkby et al., 2011). However, at many locations sulfuric acid concentrations are too low to explain observed particle growth rates (Birmili et al., 2003; Boy et al., 2005; Fiedler et al., 2005; Stolzenburg et al., 2005; Smith et al., 2008; Riipinen et al., 2011; Kuang et al., 2012), and most of the particle growth is likely due to condensation of organic vapours (Riipinen et al., 2012 and references therein). Importance of organic vapours is supported by the large organic fraction in larger, above $40 \mathrm{~nm}$, particles measured with an aerosol mass spectrometer (Allan et al., 2006; Jimenez et al., 2009) and the observations on the composition of smaller nanoparticles (e.g. O'Dowd et al., 2002; Smith et al., 2008; Riipinen et al., 2009; Smith et al., 2010; Laitinen et al., 2011; Bzdek et al., 2012). The significant role of organic vapours is also supported by the behaviour of particles during their growth. For instance, in a boreal forest region, particle growth rates vary seasonally with maximum during summer when the organic emissions peak as well (Dal Maso et al., 2005; Hirsikko et al., 2005; Yli-Juuti et al., 2011).

It has been approximated that the compounds growing atmospheric nanoparticles should have an equilibrium vapour pressure of $10^{-7} \mathrm{~Pa}$ or less (Donahue et al., 2011; Pierce et al., 2011). These low-volatility organic compounds can be produced by gas phase oxidation from the volatile organic compounds emitted to the atmosphere from biogenic and anthropogenic sources (Kroll and Seinfeld, 2008). However, many of the oxidation products of organic vapours identified in the atmosphere have higher saturation vapour pressures than required for condensation on nanoparticles (Goldstein and Galbally, 2007), and short-chain organic acids as well as aliphatic amines that have higher saturation vapour pressures have been observed in nanoparticles (Smith et al., 2010; Laitinen et al., 2011). This suggests that gas phase oxidation and reversible condensation are not the only processes explaining nanoparticle growth (see also Donahue et al., 2011; Pierce et al., 2011) and that particle phase processes, like polymerization (Limbeck et al., 2003) and salt formation (Barsanti et al., 2009), may have an important role in lowering the volatility of condensing organic compounds. The importance of different particle phase processes probably depends on particle size (Riipinen et al., 2012; Zhang et al., 2012). While polymerization is likely important for larger than $20 \mathrm{~nm}$ particles, salt formation is thought to be more important for the growth of the smallest, sub- $20 \mathrm{~nm}$, particles (Riipinen et al., 2012).
Numerous different amines have been detected in the atmosphere - both in the gas and particle phases. The low molecular weight aliphatic amines, such as dimethylamine (DMA) or trimethylamine (TMA), are the most abundant (for a review on atmospheric observations of amines see $\mathrm{Ge}$ et al., 2011a). Low molecular weight aliphatic amines are highly water soluble compounds and can therefore dissolve into aqueous aerosol particles. Many of them, e.g. DMA, are strong bases and can thus compete with ammonia in neutralizing acids in the particle phase. Quantum chemistry calculations (Kurtén et al., 2008; DePalma et al., 2012; Ortega et al., 2012) indicate that amines enhance the sulfuric acid driven nucleation more effectively than ammonia due to the stronger basicity of amines and evidence of this has also been seen in laboratory studies (Berndt et al., 2010). Both laboratory studies (Murphy et al., 2007; Berndt et al., 2010; Smith et al., 2010; Qiu and Zhang, 2013) and theory (Murphy et al., 2007; Barsanti et al., 2009) suggest that amines also participate in the growth of the particles formed by nucleation. Most of the contribution of amines in particle growth is assumed to be due to formation of aminium salts; however, non-salt contribution of amines on particle mass has also been observed, presumably due to partitioning of low-volatility oxidation products of amines into particle phase (Murphy et al., 2007).

In this study we investigate the effect of acid-base chemistry on the growth of atmospheric nanoparticles based on state-of-the-art thermodynamics of amine-containing systems. We developed a new particle growth model MABNAG (Model for Acid-Base chemistry in NAnoparticle growth) which accounts for acid dissociation and base protonation in the particle phase. Using the model we study the potential role of salt formation on particle growth rates, with particular focus on organic salts. The aim is to make an upper limit estimate of the possible effects that salt formation could have on nanoparticle growth. With this in mind, we choose dimethylamine, which is a relatively strong organic base, to represent all the amines involved in the particle growth and all the other condensing organic compounds we represent as one organic acid. We focus on four research questions: (1) what concentrations of organic acid and amine are needed to explain the atmospheric nanoparticle growth rates when acidbase chemistry is taken into account and what should the saturation vapour pressure of the organic acid be; (2) what are the relative roles of ammonia and amine in the salt formation and particle growth; (3) how does the relative humidity affect the salt formation and particle growth; and (4) how do the properties of the organic acid affect the salt formation and particle growth.

\section{Model description}

In this study we have developed the particle growth model MABNAG (Model for Acid-Base chemistry in NAnoparticle 


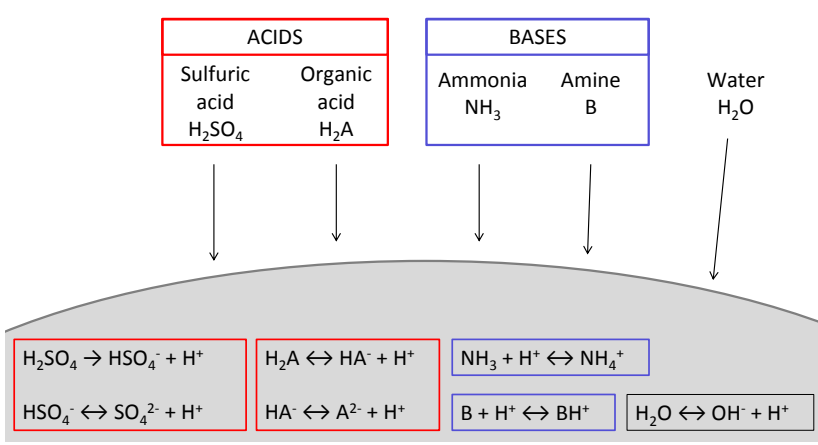

Fig. 1. Gas-liquid system modelled in this study with MABNAG. Two acids, two bases and water condense on the particle. In the particle phase, the dissociation/protonation produces ions and as a result 12 chemical species are included in the particle phase chemistry calculations.

Growth). It is a monodisperse growth model for aerosol particles. In addition to condensation of vapours onto particles, particle phase acid dissociation and base protonation are taken into account in MABNAG. To calculate particle phase chemistry, MABNAG couples dynamic condensation calculations to the Extended Aerosol Inorganics Model (E-AIM) (http://www.aim.env.uea.ac.uk; Clegg et al., 1992; Clegg and Seinfeld, 2006a, b; Wexler and Clegg, 2002), which is a phase equilibrium model. Using ambient vapour concentrations together with initial particle size and composition as inputs, MABNAG predicts the time evolution of the particle size and composition.

The condensing vapours can include both inorganic and organic compounds. Here, MABNAG is applied for a system with five compounds in the gas phase: two acids, two bases and water (Fig. 1). Acids are sulfuric acid and an organic di-acid. Bases are ammonia and an amine. All five gas phase compounds are allowed to condense onto the particle according to their abundance in the gas phase and their equilibrium vapour pressures.

The condensation of acids is calculated based on their mass fluxes in the gas phase. The change in mass of each of the acids in the particle phase is calculated according to Fuchs and Sutugin (1970); Lehtinen and Kulmala (2003):

$$
\frac{\mathrm{d} m_{i}}{\mathrm{~d} t}=\frac{2 \pi\left(d_{\mathrm{p}}+d_{i}\right)\left(D_{\mathrm{p}}+D_{i}\right) \beta_{\mathrm{m}, i} M_{i}}{R T}\left(p_{i}-p_{\mathrm{eq}, i}\right),
$$

where $d$ is diameter, $D$ is diffusion coefficient, $M_{i}$ is the molar mass of vapour $i, R$ is gas constant, $T$ is temperature, and $p_{i}$ and $p_{\text {eq, } i}$ are the ambient partial pressure and equilibrium vapour pressure of vapour $i$, respectively. Subscripts $\mathrm{p}$ and $i$ refer to the particle and the vapour $i$, respectively. The mass flux in Eq. (1) is based on the vapour-molecule collision rate suggested by Lehtinen and Kulmala (2003) where the motion of particle and the volume of vapour molecule are accounted for. In Eq. (1) the Fuchs-Sutugin transition regime correction factor for mass transport is (Fuchs and Sutugin, 1970)

$$
\beta_{\mathrm{m}, i}=\frac{1+K n_{i}}{1+\left(\frac{4}{3 \alpha_{\mathrm{m}, i}}+0.377\right) K n_{i}+\frac{4}{3 \alpha_{\mathrm{m}, i}} K n_{i}^{2}},
$$

and here it is calculated defining Knudsen (Kn) number as (Lehtinen and Kulmala, 2003)

$K n_{i}=\frac{2 \lambda_{i}}{\left(d_{\mathrm{p}}+d_{i}\right)}$,

where the mean free path $(\lambda)$ for condensation of vapour $i$ is

$\lambda_{i}=\frac{3\left(D_{\mathrm{p}}+D_{i}\right)}{\left(\bar{c}_{\mathrm{p}}^{2}+\bar{c}_{i}^{2}\right)^{1 / 2}}$.

Here, $c_{\mathrm{p}}$ and $c_{i}$ are the thermal speeds of respectively the particle $\mathrm{p}$ and vapour molecule $i$, and $\alpha_{\mathrm{m}, i}$ is mass accommodation coefficient.

In this version of MABNAG, equilibrium between gas and liquid phase is assumed to hold for water and basic compounds and their amount in the particle during each time step is calculated according to

$p_{\mathrm{eq}, i}=p_{i}$,

where $i$ refers now to water or either of the bases. The characteristic time of change of equilibrium vapour pressure of compound $i$ (as a result of composition change due to condensation) for aqueous solution is $\tau_{\mathrm{a}, i}=m_{\mathrm{w}} / K_{i} \times \tau_{\mathrm{s}, i}$ (Seinfeld and Pandis, 2006) where $m_{\mathrm{w}}$ is the total mass of liquid water and $K_{i}$ is the equilibrium constant. The characteristic time for uptake of compound $i$ from gas phase to particles by diffusion is $\tau_{\mathrm{s}, i}=1 /\left(4 \pi N D_{i} \beta_{\mathrm{m}, i}\right)$, where $N$ is the particle number concentration (Seinfeld and Pandis, 2006; Riipinen et al., 2010; Saleh et al., 2011). For multicomponent particles, $\tau_{\mathrm{a}, i}$ can be approximated as $\tau_{\mathrm{a}, i}=$ $N n_{\text {tot }} \mathrm{RTX}_{\mathrm{i}^{\prime}} / p_{\mathrm{eq}, i} \times \tau_{\mathrm{s}, i}$, where $n_{\text {tot }}$ is total moles in one particle and $X_{i^{\prime}}$ is the sum of particle phase molar fractions of $i$ and its ions (in the case of an acid or a base). The characteristic timescale $\tau_{\mathrm{s}, i}$ of the diffusion of vapour $i$ towards a given particle population is proportional to the inverse of the diffusion coefficient and transition regime correction factor for $i,\left(D_{i} \beta_{\mathrm{m}, i}\right)^{-1}$, thus decreasing with decreasing molecular mass of the condensing vapour.

Consequently, $\tau_{\mathrm{s}, i}$ for sulfuric acid is two times longer compared to water and ammonia, 1.5 times longer compared to amine, and similar or slightly shorter compared to the organic acid (see Table 1 for the properties of the organic compounds).

However, due to the large differences in the equilibrium vapour pressures of the vapours, $\tau_{\mathrm{a}, i}$ has larger differences between the compounds. For typical particle sizes and compositions in our simulations, $\tau_{\mathrm{a} \text {,water }}$ is less than a second, $\tau_{\mathrm{a}, \text { ammonia }}$ is of the order of few seconds, $\tau_{\mathrm{a} \text {,amine }}$ is of the 
order of tens of seconds, $\tau_{\mathrm{a} \text {,organic acid }}$ ranges from the order of minute to few hours while $\tau_{\mathrm{a} \text {, sulfuric acid }}$ is more than several days. Therefore, equilibration of water and ammonia is expected to be clearly faster than condensation of the acids and the timescale of the particle growth. However, in some cases $\tau_{\mathrm{a} \text {,amine }}$ can be comparable to $\tau_{\mathrm{a} \text {,organic acid. }}$. The equilibrium assumption might thus slightly overestimate the condensation of amines, so it serves the purpose of testing for the maximum possible contribution of salt formation to nanoparticle growth. This assumption should, however, be carefully tested in future studies where more detailed analysis on the condensation of specific compounds are investigated (e.g. if used for interpretation of laboratory experiments).

Particle phase chemistry and particle size affect condensation through the equilibrium vapour pressures (e.g. Seinfeld and Pandis, 2006):

$p_{\mathrm{eq}, i}=\gamma_{i}\left(X_{i},\left\{X_{j}\right\}\right) \cdot X_{i} \cdot p_{\mathrm{sat}, i}(T) \cdot \exp \left(\frac{4 \sigma v_{i}}{R T \mathrm{~d}_{\mathrm{p}}}\right)$,

where $\gamma_{i}$ is activity coefficient, which depends on the composition of the particle, $X_{i}$ and $X_{j}$ are molar fractions of respectively condensing species $i$ and the other compounds $j$ in the particle, and $p_{\mathrm{sat}, i}$ is the saturation vapour pressure above pure liquid $i$. The exponential term in Eq. (6) is the size-dependent Kelvin term where $\sigma$ and $v_{i}$ are respectively the surface tension of the solution and molar volume of $i$ in the liquid.

In the particle phase, acid dissociation and base protonation are taken into account. The organic acids included in this study were di-acids. Thus, the organic acid $\left(\mathrm{H}_{2} \mathrm{~A}\right)$ has two dissociation products ( $\mathrm{HA}^{-}$and $\mathrm{A}^{2-}$ ), as does sulfuric acid:

$\mathrm{H}_{2} \mathrm{~A} \rightarrow \mathrm{HA}^{-}+\mathrm{H}^{+}$

$\mathrm{HA}^{-} \rightarrow \mathrm{A}^{2-}+\mathrm{H}^{+}$.

In this study, the amine was dimethylamine (DMA), which is an organic base (B) that has one protonation product $\left(\mathrm{BH}^{+}\right)$, as does ammonia:

$\mathrm{B}+\mathrm{H}^{+} \rightarrow \mathrm{BH}^{+}$.

The fraction of dissociated acids and protonated bases are defined by the acid dissociation constants. Sulfuric acid is a strong acid and in E-AIM its first dissociation $\left(\mathrm{H}_{2} \mathrm{SO}_{4} \rightarrow\right.$ $\mathrm{HSO}_{4}^{-}+\mathrm{H}^{+}$) is assumed always to be complete in the aqueous phase (Clegg and Brimblecombe, 1995). Second dissociation of sulfuric acid $\left(\mathrm{HSO}_{4}^{-} \rightarrow \mathrm{SO}_{4}^{2-}+\mathrm{H}^{+}\right.$) and protonation/dissociation of bases and organic acids are treated explicitly in the model. Also, water dissociation to $\mathrm{OH}^{-}$and $\mathrm{H}^{+}$ions is taken into account. Thus, in total, 12 different species are considered in the liquid phase chemistry calculations.
The particle phase acid dissociation/base protonation and composition dependence of equilibrium vapour pressures are calculated in MABNAG with E-AIM (Clegg et al., 1992; Clegg and Seinfeld, 2006a, b; Wexler and Clegg, 2002). EAIM is a thermodynamic phase equilibrium model that can be used for systems with gas, aqueous, hydrophobic liquid and solid phases. In MABNAG, E-AIM is set to allow only the gas and aqueous phases. For mixtures of inorganic and organic compounds, E-AIM considers all the compounds when calculating activity of water. However, interactions between inorganic and organic compounds are neglected. The activity coefficients of water and solutes are first calculated based on separate purely inorganic and organic aqueous solutions of same molalities of solutes as in the mixed inorganic-organic mixture. The water activity is then calculated as a product of water activities of the inorganic and organic solutions (Eq. 9 in Clegg and Seinfeld, 2006a; Clegg et al., 2001). For solutes the activity coefficients are assumed to be the same as in the purely inorganic or organic solution. In this study, the group contribution method UNIFAC (UNIQUAC (UNIversal QUAsiChemical) Functional-group Activity Coefficients) with standard set of parameters (Fredenslund et al., 1975; Hansen et al., 1991; Wittig et al., 2003; Balslev and Abildskov, 2002) was chosen as the activity model for the neutral form of the organic compounds in E-AIM. The activity coefficients of water and inorganic ions are calculated according to Pitzer, Simonson and Clegg equations (Clegg et al., 1992) in E-AIM. The same method is applied also for the organic ions. However, due to the lack of data for organic ions the interaction parameters of inorganic ions are used for organic ions: $\mathrm{HSO}_{4}^{-}$and $\mathrm{SO}_{4}^{2-}$ for singly and doubly charged organic anions, respectively, and $\mathrm{NH}_{4}^{+}$for singly charged organic cations.

E-AIM is an equilibrium model and, therefore, while MABNAG calculates the dynamics of condensation, the liquid phase is assumed to equilibrate instantaneously regarding the acid-base chemistry. E-AIM itself does not take into account surface curvature for gas-liquid equilibrium (see Eq. 6). For nanoparticles the surface curvature can have a large effect and therefore the equilibrium vapour pressures obtained from E-AIM are corrected for Kelvin effect in MABNAG by multiplying with the exponential term in Eq. (6). For bases and water this requires using E-AIM iteratively to find the equilibrium described in Eq. (5) according to gas phase partial pressures and equilibrium vapour pressures presented in Eq. (6).

\section{Model calculations}

\subsection{Modelled system and the properties of compounds}

The system modelled in this study contained sulfuric acid, one organic acid, ammonia, one amine and water in the gas phase and all of them were allowed to condense on the 
Table 1. Properties of organic compounds used in the model.

\begin{tabular}{|c|c|c|c|}
\hline & Organic acid 1 & Organic acid 2 & Amine \\
\hline Molar mass $\left(\mathrm{g} \mathrm{mol}^{-1}\right)$ & 104 & 189 & 45 \\
\hline Molecular structure & Malonic acid & Pinic acid $^{\mathrm{a}}$ & Dimethylamine \\
\hline $\mathrm{pK}_{\mathrm{a}, 1}($ at $298.15 \mathrm{~K})$ & 2.85 & 4.62 & $10.73^{b}$ \\
\hline $\mathrm{pK}_{\mathrm{a}, 2}($ at $298.15 \mathrm{~K})$ & 5.70 & $5.70^{\mathrm{c}}$ & - \\
\hline Enthalpy change for $\mathrm{pK}_{\mathrm{a}, 1}\left(\mathrm{~kJ} \mathrm{~mol}^{-1}\right)$ & 0 & 0 & 49.45 \\
\hline Enthalpy change for $\mathrm{pK}_{\mathrm{a}, 2}\left(\mathrm{~kJ} \mathrm{~mol}^{-1}\right)$ & 0 & 0 & - \\
\hline Saturation vapour pressure $p_{\text {sat }}(\mathrm{Pa})^{\mathrm{d}}$, & & & - \\
\hline base case & $10^{-6}$ & $10^{-6}$ & - \\
\hline tested value & $10^{-5}-10^{-6}$ & $10^{-5}-10^{-7}$ & \\
\hline Henry's law constant $\mathrm{K}_{\mathrm{H}}$ (at $\left.298.15 \mathrm{~K}\right)\left(\mathrm{mol} \mathrm{kg}^{-1} \mathrm{~atm}^{-1}\right)^{\mathrm{d}}$ & - & - & $31.41^{\mathrm{e}}$ \\
\hline Enthalpy change for $\mathrm{K}_{\mathrm{H}}\left(\mathrm{kJ} \mathrm{mol}^{-1}\right)$ & - & - & $33.26^{\mathrm{e}}$ \\
\hline Diffusion coefficient $D\left(\mathrm{~m}^{2} \mathrm{~s}^{-1}\right)^{\mathrm{f}}$ & $8.9 \times 10^{-6}$ & $4.9 \times 10^{-6}$ & $11.2 \times 10^{-6}$ \\
\hline
\end{tabular}

${ }^{a}$ Activity coefficient for organic compounds were calculated in E-AIM with the UNIFAC standard set of parameters and no non-aromatic rings are included. Therefore, cyclic groups were assumed to have straight-chain group properties. ${ }^{b} \mathrm{Ge}$ et al., $2011 \mathrm{~b}$; measured value from Lide (2009). ${ }^{\mathrm{c}}$ Value of $\mathrm{pK}_{\mathrm{a}, 2}$ for pinic acid was not found in the literature so value of $\mathrm{pK}_{\mathrm{a}, 2}$ of malonic acid was used also for the organic acid 2. In general, the $\mathrm{pK}_{\mathrm{a}, 2}$ of organic di-acids vary little compared to $\mathrm{pK}_{\mathrm{a}, 1} \cdot{ }^{\mathrm{d}}$ Volatility of organic compounds was given in the model by assigning either saturation vapour pressure (organic acid) or Henry's law coefficients (amine). ${ }^{\mathrm{e}} \mathrm{Ge}$ et al., $2011 \mathrm{~b}$; measured value from NIST (National Institute of Standards and Technology) Chemistry WebBook (http://webbook.nist.gov/chemistry). ${ }^{\mathrm{f}}$ Calculated at $283.15 \mathrm{~K}$ with the method of Fuller et al. (Eq. 11-4.4 in Poling et al., 2001).

particle. The properties of dimethylamine (DMA) were used for the amine (Ge et al., 2011b), and for the organic acid two model compounds with different properties were tested (Table 1). Organic acid 1 resembles malonic acid, being the smaller and stronger of the organic acids, whereas organic acid 2 is a larger and weaker acid like pinic acid. For both of the organic acids, different saturation vapour pressures were tested (Table 1). This was done since saturation vapour pressures of different organic acids vary over several orders of magnitude (Goldstein and Galbally, 2007). The lower limit, $10^{-7} \mathrm{~Pa}\left(\approx 2.6 \times 10^{7} \mathrm{~cm}^{-3}\right)$, corresponds to the previous estimates on saturation vapour pressure required for condensation onto atmospheric nanoparticles without particle phase processes taking place (Pierce et al., 2011). The upper limit $10^{-5} \mathrm{~Pa}\left(\approx 2.6 \times 10^{9} \mathrm{~cm}^{-3}\right)$ approximately corresponds to the saturation vapour pressures of larger dicarboxylic acids, e.g. pinic acid, but is significantly lower than what is measured for short-chain organic acids, e.g. malonic acid (Pope et al., 2010).

In this study, all organic compounds, except amines, were grouped in one and treated as a single organic acid in the model. While there can be other organic compounds condensing on atmospheric nanoparticles, this assumption was made in order to have an upper limit estimate for the contribution of the salts. For the same reason, in many of the simulations (see Sect. 3.2) properties of the organic acid 1 were chosen for the organic acid. Also, grouping all amines in one and using the properties of DMA as representative of this organic base supports the aim of making an upper limit estimate of salt formation.

The properties related to liquid phase chemistry and gas-liquid equilibrium for inorganic compounds are built into E-AIM. Particle density and surface tension were as- sumed to be independent of particle composition and values $\rho=1500 \mathrm{~kg} \mathrm{~m}^{-3}$ and $\sigma=30 \mathrm{mN} \mathrm{m}^{-1}$ were used, respectively. For each compound $i$ the molar volume in liquid was approximated as $v_{i}=M_{i} / \rho$. Mass accommodation coefficients of all the compounds were assumed to be 1.0.

\subsection{Inputs in simulations}

In all of the simulations the model was initialized with 20 molecules of sulfuric acid, 20 molecules of organic acid and equilibrium amount of ammonia, amine and water, which gave an initial particle diameter of approximately $2.5 \mathrm{~nm}(4500-7000 \mathrm{u})$. Gas phase concentrations of acids and bases, relative humidity $(\mathrm{RH})$ and temperature were varied in simulations, according to Table 2 . Within a simulation, ambient conditions were assumed to stay constant in order to separate size dependence from time dependence. The simulations were set to run for $12 \mathrm{~h}$ time periods or, in case of fast growth, until the particle diameter was $40 \mathrm{~nm}$. The focus was on sub-20 nm particle growth as organic salt formation is expected to be more important in this size range compared to larger particles (Riipinen et al., 2012). Also, after $20 \mathrm{~nm}$ the simulated particle composition changed only slightly, giving no reason to continue the model runs to much larger sizes.

Five types of simulations were performed:

1. Concentrations of organic acid and amine needed for realistic atmospheric particle growth rates were studied based on a set of simulations where concentrations of organic acid and amine were varied within the higher and the lower limits presented in Table 2. In these simulations, concentrations of sulfuric acid and ammonia, $T$ and RH were set to base case values (Table 2) and properties of organic acid 1 (Table 1) 
Table 2. Ambient conditions in simulations. Base case values represent typical conditions at Hyytiälä and low and high refer to the limits of the range that was tested (see Appendix A for the estimation of these values). The last column gives the ambient conditions used for the case study day simulation.

\begin{tabular}{lrrrr}
\hline & Low & Base case & High & Case study \\
\hline sulfuric acid & $10^{6} \mathrm{~cm}^{-3}$ & $10^{6} \mathrm{~cm}^{-3}$ & $10^{8} \mathrm{~cm}^{-3}$ & $3 \times 0^{6} \mathrm{~cm}^{-3}$ \\
organic acid & $10^{7} \mathrm{~cm}^{-3}$ & $10^{8} \mathrm{~cm}^{-3}$ & $10^{9} \mathrm{~cm}^{-3}$ & $2 \times 10^{8} \mathrm{~cm}^{-3}$ \\
ammonia & $10^{8} \mathrm{~cm}^{-3}$ & $10^{9} \mathrm{~cm}^{-3}$ & $10^{11} \mathrm{~cm}^{-3}$ & $2 \times 10^{10} \mathrm{~cm}^{-3}$ \\
amine & $10^{8} \mathrm{~cm}^{-3}$ & $10^{9} \mathrm{~cm}^{-3}$ & $10^{10} \mathrm{~cm}^{-3}$ & $1 \times 10^{9} \mathrm{~cm}^{-3}$ \\
RH & $40 \%$ & $40 \%$ & $90 \%$ & $50 \%$ \\
$T$ & $283.15 \mathrm{~K}$ & $283.15 \mathrm{~K}$ & $283.15 \mathrm{~K}$ & $283.15 \mathrm{~K}$ \\
\hline
\end{tabular}

were used. These simulations were repeated for several values of saturation vapour pressure of organic acid $\left(10^{-7}-10^{-5} \mathrm{~Pa}\right)$.

2. Effect of basic vapour concentrations on the dissociation of organic acid and particle growth rate (GR) was studied based on simulations where ammonia and amine concentrations were varied (see Table 2). This also allowed for studies on the relative role of the two bases. For these calculations, the base case values of sulfuric acid concentration, $T$ and $\mathrm{RH}$, were used (Table 2). Concentration and saturation vapour pressure of the organic acid were set to respectively $3 \times 10^{8} \mathrm{~cm}^{-3}$ and $10^{-6} \mathrm{~Pa}$ based on the results of the simulation set 1 (see also Sect. 4). Other properties of the organic acid were as for organic acid 1 (Table 1).

3. Effect of water on the particle growth was studied based on simulations where RH was varied. For these simulations, the base case values of sulfuric acid, ammonia and amine were used (Table 2), concentration and saturation vapour pressure of the organic acid were set to $3 \times 10^{8} \mathrm{~cm}^{-3}$ and $10^{-6} \mathrm{~Pa}$ and other properties of organic acid were as for organic acid 1 (Table 1).

4. To investigate the effect of the chemical and physical properties of the organic acid, a set of simulations was performed where one or several properties of the organic acid were varied from those of organic acid 1 to those of organic acid 2 (Table 1). For these simulations, the base case values of sulfuric acid and $\mathrm{RH}$ were used (Table 2) and concentration and saturation vapour pressure of the organic acid were set to respectively $3 \times 10^{8} \mathrm{~cm}^{-3}$ and $10^{-6} \mathrm{~Pa}$. Base case values or elevated concentrations were used for ammonia and amine.

5. A set of simulations was performed for a case study day, 23 July 2010, at Hyytiälä, which is a boreal forest background site situated in southern Finland (Hari and Kulmala, 2005). First, the average ambient conditions
(Table 2; see Appendix A for details of the measurements) with varied saturation vapour pressure of the organic acid were used in the model, and, second, the organic acid and amine concentrations were varied in the model. The case study day simulations allowed us a direct comparison between the simulated and measured GR. For these simulations, properties of organic acid 1 were used.

The base case values and the limits of ambient conditions are based on typical conditions at the Hyytiälä measurement station. For details, see Appendix A.

The GR calculated from the simulated particle growth was compared to GR calculated based on particle distributions measured at Hyytiälä. For Hyytiälä, particle growth rates are most often calculated based on total particle population measured with differential mobility particle sizer (DMPS; Aalto et al., 2001) or based on naturally charged particle population measured with one of the ion spectrometers, air ion spectrometer (Mirme et al., 2007) or balanced scanning mobility analyzer (Tammet, 2006). While the DMPS setup used in Hyytiälä is equipped with a dryer and thus measures dry particle size, the two ion spectrometers measure wet particle size. Studies using and comparing the GRs from the different instruments show that in most of the cases, except in conditions with very high RH, the difference between GRs calculated from dry and wet sizes is small and does not affect the results significantly (Dal Maso et al., 2005; Hirsikko et al., 2005; Yli-Juuti et al., 2011). In this study, the GR from the model simulations was thus calculated based on the dry particle size.

\section{Results and discussion}

\subsection{The effect of organic acid and amine concentrations - simulation set 1}

In simulation set 1 , concentrations of the organic acid and amine and saturation vapour pressure of the organic acid were varied while concentrations of sulfuric acid and ammonia and RH were kept constant in order to study the concentrations of organic acid and amine needed for atmospheric nanoparticle growth. Figure 2 shows the predicted GR of particles 3-7 nm in diameter as a function of gas phase concentrations of amine and organic acid with four different saturation vapour pressures of the organic acid. The concentration ranges on the $x$ and $y$ axes represent reasonable organic acid and amine concentrations, respectively, at Hyytiälä (Table 2; see also Appendix A).

The organic acid concentration required in the model to predict similar GRs as observed in the atmosphere depends strongly on the assumed saturation vapour pressure of the organic acid. Typically, GR of 3-7 nm particles varies at Hyytiälä within $1-10 \mathrm{~nm} \mathrm{~h}^{-1}$ with the average $3.8 \mathrm{~nm} \mathrm{~h}^{-1}$ (Dal Maso et al., 2005; Hirsikko et al., 2005; Yli-Juuti et al., 
2011). By assuming the $p_{\text {sat, Org. acid }}$ of $1 \times 10^{-7} \mathrm{~Pa}$, growth rates comparable to measured values were predicted with about $1 \times 10^{8} \mathrm{~cm}^{-3}$ organic acid concentrations, which corresponds to the base case value in Table 2 . As $p_{\text {sat, Org. acid }}$ was increased, higher concentration of organic acid were naturally required in the model to reach the GRs observed in the atmosphere. With $p_{\text {sat, Org. acid }}$ up to $1 \times 10^{-6} \mathrm{~Pa}$, MABNAG still predicted GRs to reach the values observed in the atmosphere with reasonable assumptions about the organic acid concentrations. When $p_{\text {sat, Org. acid was set higher than }}$ $1 \times 10^{-6} \mathrm{~Pa}$, unrealistically high organic acid concentrations (over $10^{9} \mathrm{~cm}^{-3}$ ) were needed to grow the particles with GRs equal to the atmospheric GRs.

The saturation vapour pressure of $10^{-6} \mathrm{~Pa}$ is only one order of magnitude higher than the values derived without including any particle phase processes (e.g. Pierce et al., 2011). This implies that the organic salt formation is not able to fully explain the apparent gap between the saturation vapour pressures required for the molecules to condense onto nanoparticles and those observed in laboratory for organic compounds. Since the range of organic acid concentrations considered here was rather wide, the result is likely to apply also for many other environments, except for those with high base concentrations (see Sect. 4.2).

The higher the amine concentration the lower the organic acid concentration needed to produce GRs comparable to atmospheric observations (Fig. 2). However, amine concentration affected the GR less than organic acid concentration. For example, the GR of 3-7 nm particles was rather insensitive to changes in amine concentration below $10^{9} \mathrm{~cm}^{-3}$, and one order of magnitude increase of amine concentration from $10^{8} \mathrm{~cm}^{-3}$ to $10^{9} \mathrm{~cm}^{-3}$ did not change the predicted GR significantly. An increase from $10^{9} \mathrm{~cm}^{-3}$ to $10^{10} \mathrm{~cm}^{-3}$ in amine concentration decreased the organic acid concentration needed for $1 \mathrm{~nm} \mathrm{~h}^{-1}$ growth rate by less than a factor of two.

\subsection{The role of ammonia and amine - simulation set 2}

In most of the model calculations, a major part of the particle growth was due to condensation of the organic acid. Varying the concentrations of basic vapours affected the GR both due to the effect on dissociation of organic acid and due to the increase of particulate mass of the basic compounds. The effect of basic vapour concentrations on dissociation of organic acid and the subsequent effect on the GR were studied based on the simulation set 2 , where amine and ammonia concentrations were varied while acid concentrations and RH were kept constant. For these simulations, organic acid concentration of $3 \times 10^{8} \mathrm{~cm}^{-3}$ and $p_{\text {sat, Org. acid }}$ of $10^{-6} \mathrm{~Pa}$ were chosen as they gave GR values comparable to atmospheric values with base case concentrations of amine and ammonia.

Figure 3 shows the fraction of organic acid that was predicted to dissociate in the particle phase. The difference in dissociated fraction between amine concentrations of
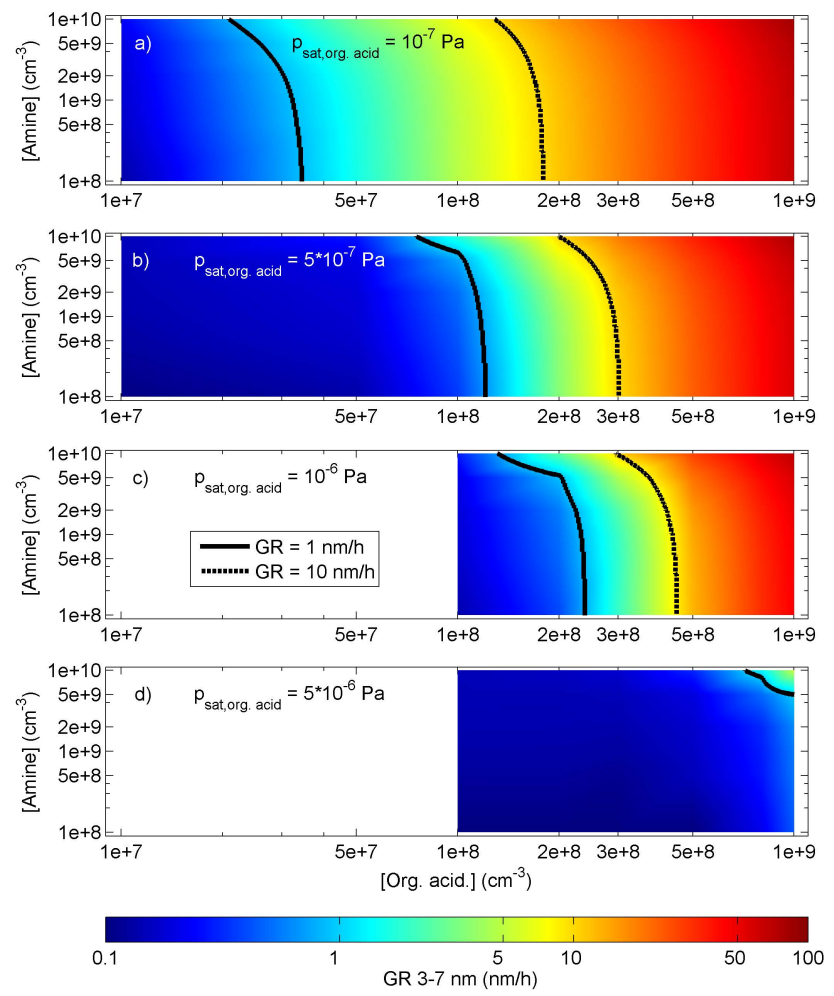

Fig. 2. Growth rate of $3-7 \mathrm{~nm}$ particles as a function of organic acid and amine concentration predicted, assuming saturation vapour pressure of organic acid to be (a) $1 \times 10^{-7} \mathrm{~Pa}$, (b) $5 \times 10^{-7} \mathrm{~Pa}$, (c) $1 \times 10^{-6} \mathrm{~Pa}$ and (d) $5 \times 10^{-6} \mathrm{~Pa}$. Concentrations of sulfuric acid $\left(10^{6} \mathrm{~cm}^{-3}\right)$ and ammonia $\left(10^{9} \mathrm{~cm}^{-3}\right)$, RH (40\%) and temperature $(283.15 \mathrm{~K})$ were set to base case values presented in Table 2 , and properties of organic acid 1 (Table 1) were used.

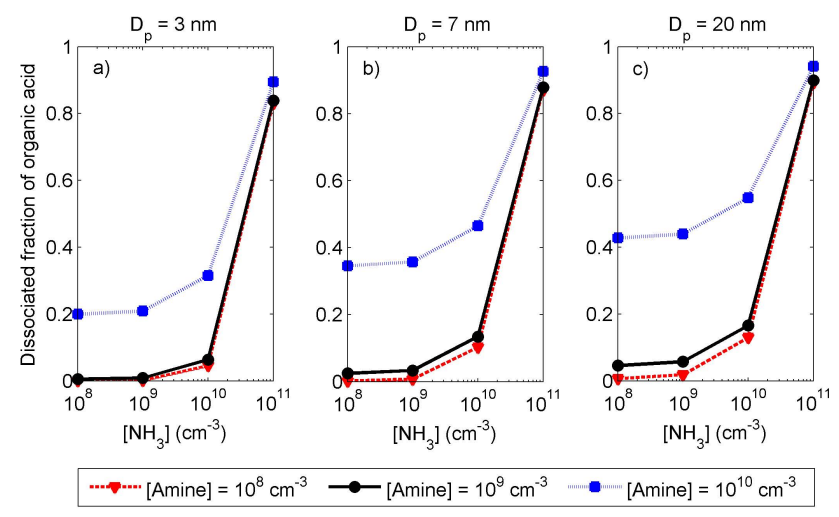

Fig. 3. Dissociated fraction of particle phase organic acid at particle sizes (a) $3 \mathrm{~nm}$, (b) $7 \mathrm{~nm}$ and (c) $20 \mathrm{~nm}$ as a function of ammonia concentration for three amine concentrations. Concentration and saturation vapour pressure of organic acid were set to $3 \times 10^{8} \mathrm{~cm}^{-3}$ and $10^{-6} \mathrm{~Pa}$, respectively. Other properties of organic acid were as for organic acid 1 (Table 1). Sulfuric acid concentration $\left(10^{6} \mathrm{~cm}^{-3}\right), \mathrm{RH}(40 \%)$ and temperature $(283.15 \mathrm{~K})$ were set to base case values in all simulations (Table 2). 
$10^{8} \mathrm{~cm}^{-3}$ and $10^{9} \mathrm{~cm}^{-3}$ was very small and in both cases only less than $20 \%$ of the organic acid dissociated unless ammonia concentration was very high, $>10^{10} \mathrm{~cm}^{-3}$. With amine concentration of $10^{10} \mathrm{~cm}^{-3}$, a considerable fraction of organic acid dissociated even at low ammonia concentrations. Amine, as a stronger base, enhances organic acid dissociation more effectively than ammonia: with amine concentration of $10^{10} \mathrm{~cm}^{-3}$ and base case concentration of ammonia, $20-44 \%$ of organic acid dissociated in the particle phase, depending on particle size; while with ammonia concentration of $10^{10} \mathrm{~cm}^{-3}$ and base case concentration of amine, only $6-17 \%$ of organic acid dissociated. The fraction of dissociated organic acid was predicted to increase with particle size at each ammonia and amine concentration.

Particle growth rates calculated from simulations corresponding to Fig. 3 are reported in Table 3. The stronger effect of amine on dissociation of the organic acid is directly reflected in growth rates. Increasing amine concentrations from $10^{9} \mathrm{~cm}^{-3}$ to $10^{10} \mathrm{~cm}^{-3}$ while keeping the ammonia concentration constant below $10^{11} \mathrm{~cm}^{-3}$ increased the GR of 3$7 \mathrm{~nm}$ particles over a factor of three. A similar increase in ammonia concentration with constant amine concentration at best doubled the GR of 3-7 nm particles. Also, the GR of 7$20 \mathrm{~nm}$ particles was affected more by the change in amine concentration than by a similar change in ammonia concentration. The neutral fraction of the organic acid condenses reversibly on the particle, while the ionized fraction is effectively non-volatile. The relative change of these fractions between different base concentrations affects the GRs shown in Table 3. When most of the organic acid remains in neutral form in the particle phase, the growth is limited by the Kelvin term and GR increases with particle size. When most of the organic acid is in the ionized form, organic acid condenses as if it was non-volatile, the Kelvin term does not limit the particle growth and GR does not increase with particle size. The latter is observed only with very high base concentrations (ammonia concentration $10^{11} \mathrm{~cm}^{-3}$ in the simulations).

In addition to affecting the dissociation of the organic acid, the basic compounds affect the particle GR through their mass fluxes to the particle. However, the increase in GR with increasing base concentration is not only due to the increased mass fluxes of bases since the bases account for less than approximately $25 \%$ of the dry particle mass. This is seen from Fig. 4 where the mass fractions of compounds are shown after removing the contribution of water. In Fig. 4, for each acid/base the neutral form and its dissociation/protonation product(s) are grouped together in order to indicate the contribution of each of the condensing vapours. The dry mass fractions are presented in order to be consistent with particle composition measurements where typically particle water content is not measured. With ammonia concentration one order of magnitude higher than amine concentration, the mass fractions of the two bases are approximately equal in the particle. With similar gas phase concentrations of amine and ammonia, amine mass is significantly higher in the parti-

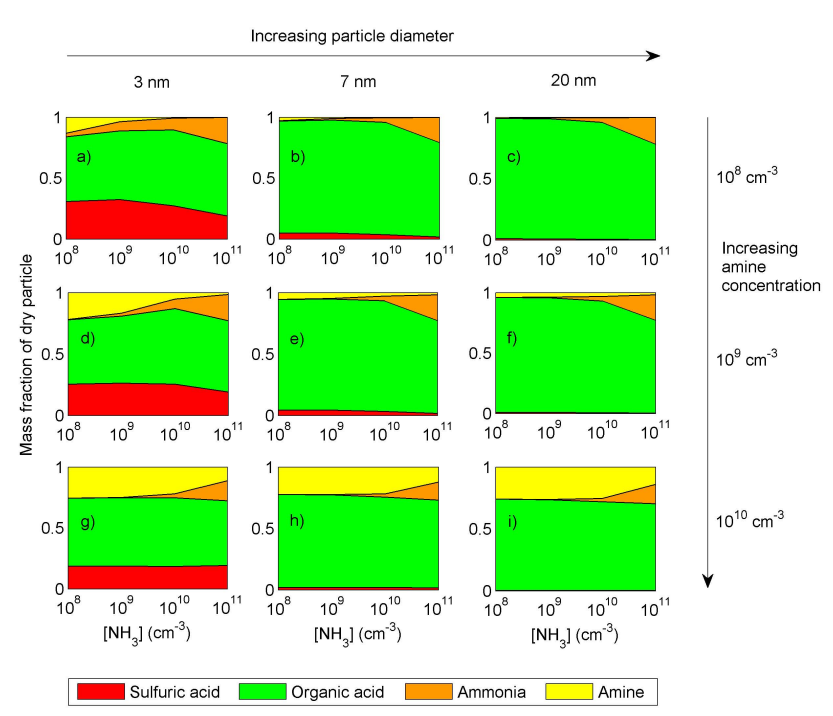

Fig. 4. Dry particle mass fractions of particles at $3 \mathrm{~nm}(\mathbf{a}, \mathbf{d}, \mathbf{g}), 7 \mathrm{~nm}$ $(\mathbf{b}, \mathbf{e}, \mathbf{h})$ and $20 \mathrm{~nm}(\mathbf{c}, \mathbf{f}, \mathbf{i})$ as a function of ammonia concentration at amine concentrations of $10^{8} \mathrm{~cm}^{-3}(\mathbf{a}, \mathbf{b}, \mathbf{c}), 10^{9} \mathrm{~cm}^{-3}(\mathbf{d}, \mathbf{e}, \mathbf{f})$ and $10^{10} \mathrm{~cm}^{-3}(\mathbf{g}, \mathbf{h}, \mathbf{i})$. Concentration and saturation vapour pressure of organic acid were set to $3 \times 10^{8} \mathrm{~cm}^{-3}$ and $10^{-6} \mathrm{~Pa}$. Other properties of organic acid were as for organic acid 1 (Table 1). Sulfuric acid concentration $\left(10^{6} \mathrm{~cm}^{-3}\right)$, RH $(40 \%)$ and temperature $(283.15 \mathrm{~K})$ were set to base case values in all simulations (Table 2).

cle phase. This is partly due to the difference in their strength as bases but also affected by their different molecular masses.

In most cases, the fraction of bases in the particle dry mass decreased as the particle size increased (Fig. 4), and, therefore, the contribution of bases on the particle mass was largest for the smallest particles. In these cases, most of the particle phase bases were used for neutralizing sulfuric acid, and as a result the mass fractions of the bases decreased simultaneously with the mass fraction of sulfuric acid during the particle growth. However, at the highest amine and ammonia concentrations, $10^{10} \mathrm{~cm}^{-3}$ and $10^{11} \mathrm{~cm}^{-3}$ respectively, there was little change in the mass fractions of base compounds during particle growth, although sulfuric acid mass fraction decreased as the particle size increased. This leads to lack of correlation between the mass fractions of sulfuric acid and the bases. Therefore, at these conditions the controlling factor for the partitioning of the bases to the particle phase seems to be their high gas phase concentrations, and the acid-base chemistry in the particle phase is driven by the bases. Figure 4 shows model simulation for base case sulfuric acid concentration $\left(10^{6} \mathrm{~cm}^{-3}\right)$ but similar behaviour in mass fractions of bases was observed with all sulfuric acid concentrations $\left(10^{6}-10^{8} \mathrm{~cm}^{-3}\right)$. Molar fractions from the same model simulations are presented in Fig. 5.

The mass fraction of sulfuric acid decreased as a function of particle size. The driving force for condensation is the difference between gas phase concentration and equilibrium vapour pressure of the condensing vapour (Eq. 1). For the 
Table 3. Growth rates of 3-7 nm and 7-20 nm particles calculated based on the dry size for three amine concentrations when concentration of $\mathrm{NH}_{3}$ was varied from the base case $\left(10^{9} \mathrm{~cm}^{-3}\right.$, first row). Organic acid concentration and saturation vapour pressure were $3 \times 10^{8} \mathrm{~cm}^{-3}$ and $10^{-6} \mathrm{~Pa}$. Sulfuric acid concentration $\left(10^{6} \mathrm{~cm}^{-3}\right)$, RH $(40 \%)$ and temperature $(283.15 \mathrm{~K})$ were set to base case values in all simulations (Table 2).

\begin{tabular}{|c|c|c|c|}
\hline & {$[$ Amine $]=10^{8} \mathrm{~cm}^{-3}$} & $\begin{array}{l}\text { GR 3-7 nm }\left(\mathrm{nm} \mathrm{h}^{-1}\right) \\
{\left[\text { Amine] }=10^{9} \mathrm{~cm}^{-3}\right.}\end{array}$ & {$[$ Amine $]=10^{10} \mathrm{~cm}^{-3}$} \\
\hline$\left[\mathrm{NH}_{3}\right]=10^{9} \mathrm{~cm}^{-3}$ & 2.0 & 2.0 & 10.5 \\
\hline$\left[\mathrm{NH}_{3}\right]=10^{8} \mathrm{~cm}^{-3}$ & 1.9 & 2.0 & 10.2 \\
\hline$\left[\mathrm{NH}_{3}\right]=10^{10} \mathrm{~cm}^{-3}$ & 3.1 & 3.8 & 14.0 \\
\hline \multirow[t]{2}{*}[\mathrm{NH}_{3}]{$=10^{11} \mathrm{~cm}^{-3}$} & 23.4 & 23.8 & 26.9 \\
\hline & {$[$ Amine $]=10^{8} \mathrm{~cm}^{-3}$} & $\begin{array}{l}\mathrm{GR} 7-20 \mathrm{~nm}\left(\mathrm{~nm} \mathrm{~h}^{-1}\right) \\
{[\text { Amine }]=10^{9} \mathrm{~cm}^{-3}}\end{array}$ & {$[$ Amine $]=10^{10} \mathrm{~cm}^{-3}$} \\
\hline$\left[\mathrm{NH}_{3}\right]=10^{9} \mathrm{~cm}^{-3}$ & 6.0 & 7.0 & 16.9 \\
\hline$\left[\mathrm{NH}_{3}\right]=10^{8} \mathrm{~cm}^{-3}$ & 5.8 & 6.8 & 16.6 \\
\hline$\left[\mathrm{NH}_{3}\right]=10^{10} \mathrm{~cm}^{-3}$ & 8.6 & 9.6 & 19.0 \\
\hline$\left[\mathrm{NH}_{3}\right]=10^{11} \mathrm{~cm}^{-3}$ & 22.5 & 22.8 & 25.4 \\
\hline
\end{tabular}

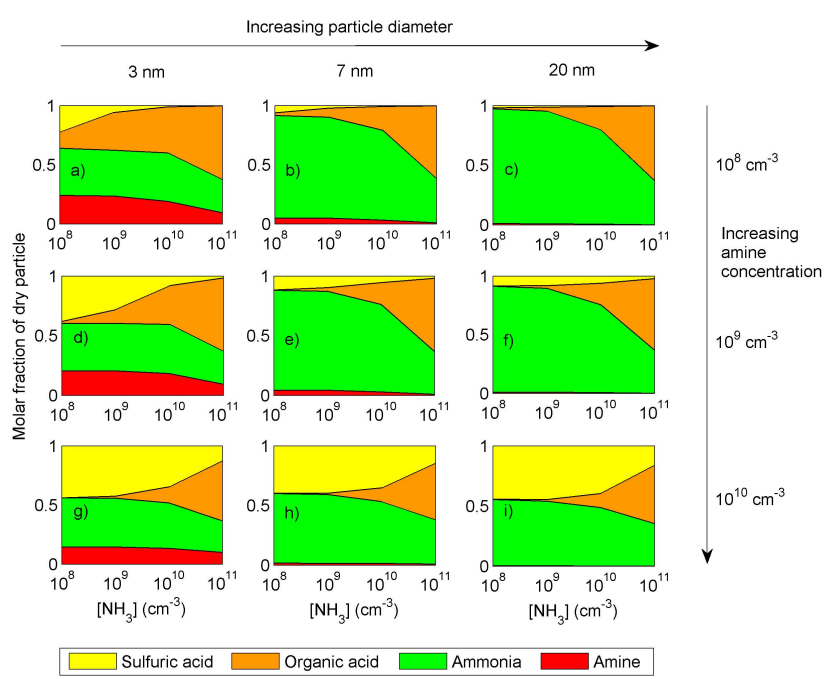

Fig. 5. Dry particle molar fractions of particles at $3 \mathrm{~nm}(\mathbf{a}, \mathbf{d}, \mathbf{g})$, $7 \mathrm{~nm}(\mathbf{b}, \mathbf{e}, \mathbf{h})$ and $20 \mathrm{~nm}(\mathbf{c}, \mathbf{f}, \mathbf{i})$ as a function of ammonia concentration at amine concentrations of $10^{8} \mathrm{~cm}^{-3}(\mathbf{a}, \mathbf{b}, \mathbf{c}), 10^{9} \mathrm{~cm}^{-3}$ (d, e, f) and $10^{10} \mathrm{~cm}^{-3}(\mathbf{g}, \mathbf{h}, \mathbf{i})$. Concentration and saturation vapour pressure of organic acid were set to $3 \times 10^{8} \mathrm{~cm}^{-3}$ and $10^{-6} \mathrm{~Pa}$. Other properties of organic acid were as for organic acid 1 (Table 1). Sulfuric acid concentration $\left(10^{6} \mathrm{~cm}^{-3}\right)$, RH (40\%) and temperature $(283.15 \mathrm{~K})$ were set to base case values in all simulations (Table 2).

smallest particles, the driving force for the condensation is comparable for the two acids. As the particles grow, driving force for condensation of the organic acid becomes stronger due to the decrease of its equilibrium vapour pressure (decrease of Kelvin effect) and its higher gas phase concentration. Sulfuric acid is a much stronger acid compared to the organic acid and therefore its dissociation is strongly preferred over dissociation of organic acid. As the underlying assumption in the model is that all the sulfuric acid, due to being so strong acid, will dissociate at least once, all the sulfuric acid is forming salt in the particle phase. This further lowers the equilibrium vapour pressure of sulfuric acid, making it effectively non-volatile and its condensation independent of the change in equilibrium vapour pressure with particle size. The increase of the dissociated fraction of organic acid with increasing particle size (Fig. 3) is also related to the differences in the dissociation constants and gas phase concentrations of the two acids, and thus their competition for the bases. The ratio of organic acid to sulfuric acid in the particle increases with particle size, and, due to this, more of the organic acid can dissociate in the larger particles, while at the smaller particles the organic acid is not strong enough to compete for the bases with the sulfuric acid.

It is worth noting that the model does not include any possible interactions between sulfuric acid and the organic acid. Formation of low-volatility compounds, e.g. organosulfates, in the particle could further enhance the condensation of organic acid. This would probably not affect the condensation of sulfuric acid as the condensation of sulfuric acid on nanoparticles seems to be limited by its gas phase concentration, and not by its equilibrium vapour pressure.

The mass fraction of salts in the particle varied both as a function of particle size and gas phase concentrations of bases (Fig. 6). The variation with the base concentration was the largest in the larger particle sizes: depending on the concentrations of the bases, $3 \%$ to $96 \%$ of particle dry mass consisted of salts at $20 \mathrm{~nm}$, while at $3 \mathrm{~nm}$ the fraction of salts varied from $40 \%$ to $95 \%$. The larger contribution of salts in particle mass of the smallest particles is due to differences in the contribution of sulfuric acid and organic acid to the 


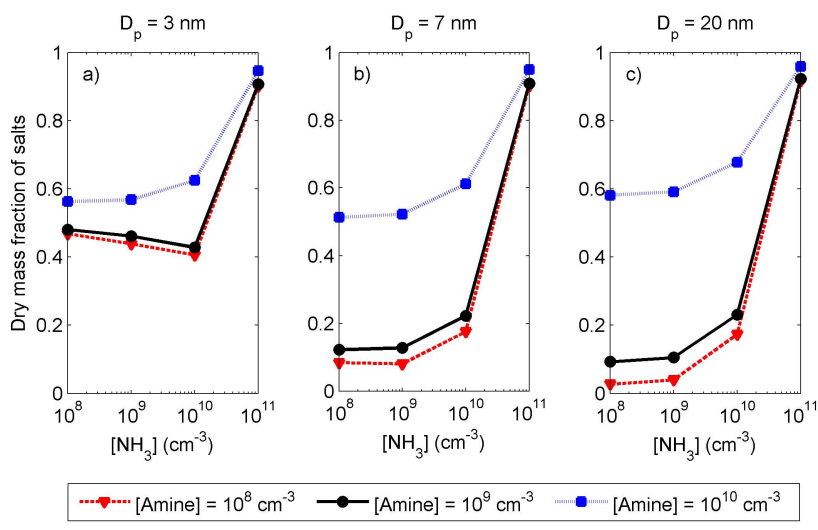

Fig. 6. Dry mass fraction of salts at particle sizes (a) $3 \mathrm{~nm}$, (b) $7 \mathrm{~nm}$ and (c) $20 \mathrm{~nm}$ as a function of ammonia concentration for three amine concentrations. Concentration and saturation vapour pressure of organic acid were set to $3 \times 10^{8} \mathrm{~cm}^{-3}$ and $10^{-6} \mathrm{~Pa}$, respectively. Other properties of organic acid were as for organic acid 1 (Table 1). Sulfuric acid concentration $\left(10^{6} \mathrm{~cm}^{-3}\right)$, RH (40\%) and temperature $(283.15 \mathrm{~K})$ were set to base case values in all simulations (Table 2).

growth since in practice all of the non-salt dry mass of the particle was due to the neutral organic acid.

\subsection{The effect of water - simulation set 3}

The effect of RH on acid-base chemistry and particle growth was tested using simulation set 3 where RH was varied from $40 \%$ to $90 \%$ while concentrations of acids and bases were kept constant. Increasing RH from $40 \%$ to $60 \%$ increased the mass fraction of water in the particle approximately by $30 \%$ (Fig. 7a and b), and GR calculated from particle dry size increased from $2.0 \mathrm{~nm} \mathrm{~h}^{-1}$ to $6.9 \mathrm{~nm} \mathrm{~h}^{-1}$ at size range 3-7 nm and from $7.0 \mathrm{~nm} \mathrm{~h}^{-1}$ to $11.8 \mathrm{~nm} \mathrm{~h}^{-1}$ at size range 7$20 \mathrm{~nm}$. At RH of $90 \%$ about half of the particle mass was water (Fig. 7c) and the GRs calculated based on particle dry size were $22.5 \mathrm{~nm} \mathrm{~h}^{-1}$ and $28.4 \mathrm{~nm} \mathrm{~h}^{-1}$ at size ranges $3-7 \mathrm{~nm}$ and 7-20 nm, respectively. The GR was calculated based on the dry mass of the particle and therefore the increase in GR is not explained by the increase in particle water content. Instead, the increased amount of water in the particles at higher RH enhanced the condensation of the other compounds: mass fraction of bases increased and consequently the dissociated fraction of organic acid also increased when RH increased.

According to these results, the effect of salt formation on the particle growth is more important at environments with high RH. These results also suggest that if the model is representing the ambient nanoparticles correctly, the ambient GRs would be expected to have a positive correlation with RH if concentrations of other vapours are constant. Such correlation is not seen in data from Hyytiälä (Yli-Juuti et al., 2011). This indicates that salt formation is likely not the limiting factor for the growth of the atmospheric 3-20 nm parti-
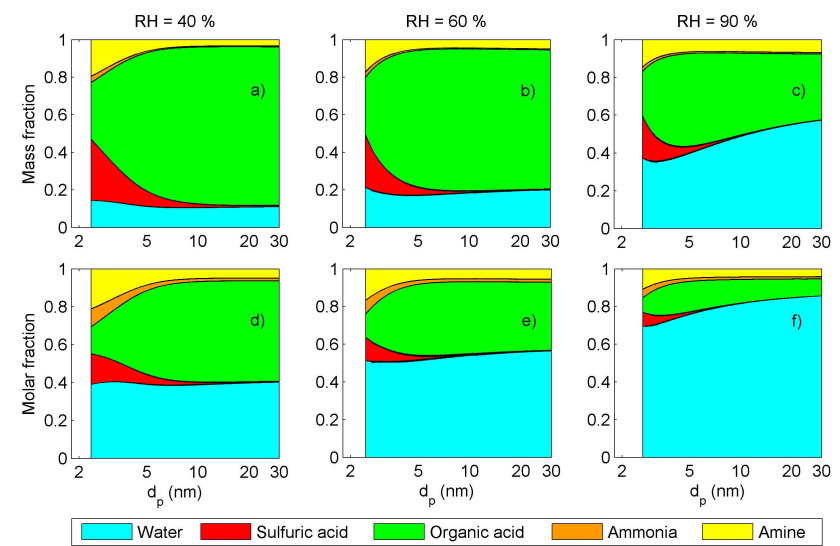

Fig. 7. Mass $(\mathbf{a}, \mathbf{b}, \mathbf{c})$ and molar $(\mathbf{d}, \mathbf{e}, \mathbf{f})$ fractions as a function particle size in simulations where RH was $40 \%$ (a, d), $60 \%(\mathbf{b}, \mathbf{e})$ and $90 \%$ (c, f). Concentrations of sulfuric acid $\left(10^{6} \mathrm{~cm}^{-3}\right)$, ammonia $\left(10^{9} \mathrm{~cm}^{-3}\right)$ and amine $\left(10^{9} \mathrm{~cm}^{-3}\right), \mathrm{RH}(40 \%)$ and temperature $(283.15 \mathrm{~K})$ were set to base case values. Concentration of organic acid was $3 \times 10^{8} \mathrm{~cm}^{-3}$ and $p_{\text {sat, }}$ org. acid was $10^{-6} \mathrm{~Pa}$.

cles - at least not with the thermodynamics considered here. However, the correlation of GR with RH could be disturbed by possible changes in the concentrations of other vapours (Hamed et al., 2011).

\subsection{The effect of properties of organic acid - simulation set 4}

For the results presented so far, the properties of organic acid 1 were used. In simulation set 4 , effect of thermodynamic properties of the organic acid were studied by changing one or several of the properties of the organic acid from those of organic acid 1 to those of organic acid 2. For these simulations, acid concentrations and RH were kept constant and different base concentrations were tested. Table 4 shows the GR in simulations where properties of the organic acid were varied from organic acid 1 to organic acid 2 (simulation set 4). Keeping all other properties of the organic acid as for organic acid 1 but using the molar mass of organic acid 2 (higher molar mass) decreased the GR by about $65 \%$ for 3 $7 \mathrm{~nm}$ particles and about $20 \%$ for $7-20 \mathrm{~nm}$ particles. This is due to the decrease of diffusion coefficient with increased molecular mass. Also, the molecular structure of the organic acid, which affects the calculation of the activity coefficients and thereby the equilibrium vapour pressure of the organic acid, affected the predicted GR. Use of the molecular structure of organic acid 2 instead of the molecular structure of organic acid 1 decreased the GRs in both size ranges by about $60 \%$. Changing the strength of the organic acid had very minor effect on the GR: using the acid dissociation constant of organic acid 2 instead of organic acid 1 decreased the GR by only a few per cent. With base case gas phase concentrations the GR of 3-7 nm particles was not affected by this change 
in dissociation coefficient. Both organic acids 1 and 2 are much weaker acids than sulfuric acid and it seems that they are too weak to drive the particle phase acid-base chemistry. The results suggest that the dissociation of organic acid is not sensitive to its dissociation constant but instead controlled by the available concentrations of the bases. The assumptions of the properties of the organic acid thus change the quantitative results but do not affect the conclusions drawn from the model results.

It is possible that the small size-scale of nanoparticles affects the thermodynamic behaviour of the compounds and that the bulk-based thermodynamics in MABNAG may not capture all the properties of nanoparticles. To study this possibility, MABNAG was compared to the conceptual growth model introduced by Riipinen et al. (2012), which considers a system of two acids and two bases but includes no water in the particles. The relative stability of the salts was accounted for with effective mass accommodation coefficients based on quantum chemical results on the evaporation rates of very small clusters (Kurtén et al., 2008) instead of detailed thermodynamics. In the conceptual model, diffusional fluxes of all the four compounds are calculated dynamically, and acids are allowed to exist in the particle phase in their acidic form or as salts formed with one of the bases in 1:1 molar ratio. Bases are allowed to exist in the particle phase only if they form salt with one of the acids and the excess base molecules are evaporated from the particles. The two models, MABNAG and the conceptual model (Riipinen et al., 2012) give qualitatively similar results on the particle growth with the same gas phase concentrations and initial composition of the particle: mass fraction of organic acid increases while mass fractions of sulfuric acid and bases decrease as the particle grows (Fig. 8). However, MABNAG predicts less amine and more ammonia, and in total less bases, in the particle compared to the conceptual growth model. This indicates that the bulk thermodynamics based MABNAG and the conceptual growth model based on quantum chemistry calculations of cluster stabilities predict different behaviour, especially for amine salts. The conceptual growth model, as it is based on stabilities of small $(1-2 \mathrm{~nm})$ molecular clusters, is more likely to work for the smallest, nanometre-sized, particles but might fail in predicting particle composition at larger sizes. MABNAG, on the other hand, is more likely to work for larger particles but might fail when particles are very small. This is also the reason why in this study MABNAG was initialized with particles of about $2.5 \mathrm{~nm}$ in diameter instead of trying to capture the cluster sizes. The differences in predictions from the two models suggest that MABNAG might lack important interactions between molecules at the smallest particle sizes. More quantitative comparisons of thermodynamic and quantum chemical approaches are thus highly desirable and make an excellent topic for future studies.

\subsection{Case study day - simulation set 5}

For the case study day, the gas phase concentrations of sulfuric acid and ammonia were obtained directly from measurements while organic acid and amine concentrations were estimated based on measurements and were thus more uncertain. When the vapour concentrations from measurements (Table 2) were used and the saturation vapour pressure of the organic acid was varied, the best agreement between measured and modelled GR was found with $p_{\text {sat,Org. acid }}$ of $10^{-6} \mathrm{~Pa}$ (Fig. 9a). With $p_{\text {sat, Org. acid }} \geq 10^{-5} \mathrm{~Pa}$, the predicted GRs were an order of magnitude lower compared to measured values with the estimated gas phase concentrations, and organic acid $\left(>8 \times 10^{8} \mathrm{~cm}^{-3}\right)$ or amine $\left(>1 \times 10^{10} \mathrm{~cm}^{-3}\right)$ concentrations that are probably unrealistically high were required in the model for particles to grow with the measured growth rates. On the other hand, with $p_{\text {sat, Org. acid }} \leq 10^{-7} \mathrm{~Pa}$ lower organic acid gas phase concentration compared to estimated value was needed in the model to reach the measured GR. In this case, the modelled GRs did not have the correct size dependence as equilibrium vapour pressure of organic acid was low enough compared to ambient partial pressure for the Kelvin effect not to affect the GRs. In the atmosphere, the organic acid concentration is likely to increase during the morning and early afternoon due to the photo-oxidation activity, and, hence, the apparent increase of GR with particle size would be predicted even with the low saturation vapour pressure if the time profiles of condensing vapours would be taken into account. Therefore, we conclude that the condensing organic acids should on average have saturation vapour pressures on the order of $10^{-6} \mathrm{~Pa}$ or lower for the model to predict GRs that are consistent with measurements on the case study day. It should be noted that this low-volatile compound could be an organic compound of any type as salt formation does not seem to be driving its condensation. This is in agreement with the results shown above for the average conditions at Hyytiälä.

Assuming $p_{\text {sat, Org. acid }}$ to be $10^{-6} \mathrm{~Pa}$, the ambient organic acid concentrations estimated from measurements seem to be rather consistent with the particle growth. The GR predicted with MABNAG was reasonable compared to the measured GR when organic acid concentration was within $\pm 50 \%$ of the estimated value. Particle growth was less sensitive to changes in amine concentration, but as amine concentration is not well constrained there is considerable uncertainty related to the effect of amine on the particle growth. Assuming lower amine concentration did not affect the predicted particle growth much since ammonia was the main base even with the amine concentration estimated from the measurements (Fig. 9b). Assuming higher amine concentration increased the GR, partly due to enhanced dissociation of organic acid, and as a consequence a lower organic acid vapour concentration was needed to explain the measured particle growth. This effect is not very strong as an order of magnitude increase in amine concentration was needed 
Table 4. Growth rates of particles calculated based on the dry size from the simulations where the properties of the organic acid were varied. First column indicates the property of organic acid which was changed from organic acid 1 to organic acid 2 (Table 1). First case ("none") has all the properties of organic acid 1 . Ammonia $\left(10^{9} \mathrm{~cm}^{-3}\right)$ and amine $\left(10^{9} \mathrm{~cm}^{-3}\right)$ concentrations were set to base case values, unless otherwise stated. Organic acid concentration and saturation vapour pressure were $3 \times 10^{8} \mathrm{~cm}^{-3}$ and $10^{-6}$ Pa. Sulfuric acid concentration $\left(10^{6} \mathrm{~cm}^{-3}\right), \mathrm{RH}(40 \%)$ and temperature $(283.15 \mathrm{~K})$ were set to base case values in all simulations (Table 2$)$.

\begin{tabular}{|c|c|c|}
\hline Changed property & $\begin{array}{r}\text { GR 3-7 nm } \\
\left(\mathrm{nm} \mathrm{h}^{-1}\right)\end{array}$ & $\begin{array}{r}\text { GR } 7-20 \mathrm{~nm} \\
\quad\left(\mathrm{~nm} \mathrm{~h}^{-1}\right)\end{array}$ \\
\hline none & 2.0 & 7.0 \\
\hline Molar mass ${ }^{\mathrm{a}}$ & 0.7 & 5.7 \\
\hline Activity coefficient ${ }^{\mathrm{b}}$ & 0.8 & 3.0 \\
\hline $\mathrm{pK}_{\mathrm{a}, 1}$ & 2.0 & 6.8 \\
\hline none, $[$ amine $]=10^{10} \mathrm{~cm}^{-3}$ & 10.5 & 16.9 \\
\hline $\mathrm{pK}_{\mathrm{a}, 1}$, [amine $]=10^{10} \mathrm{~cm}^{-3}$ & 10.0 & 16.6 \\
\hline none, $[$ amine $]=10^{10} \mathrm{~cm}^{-3},\left[\mathrm{NH}_{3}\right]=10^{10} \mathrm{~cm}^{-3}$ & 14.0 & 19.0 \\
\hline $\mathrm{pK}_{\mathrm{a}, 1},[$ amine $]=10^{10} \mathrm{~cm}^{-3},\left[\mathrm{NH}_{3}\right]=10^{10} \mathrm{~cm}^{-3}$ & 13.8 & 18.8 \\
\hline
\end{tabular}

${ }^{a}$ Molar mass affects also diffusion coefficient. ${ }^{b}$ Structure of organic acid was changed, which affects UNIFAC calculations for activity coefficients.
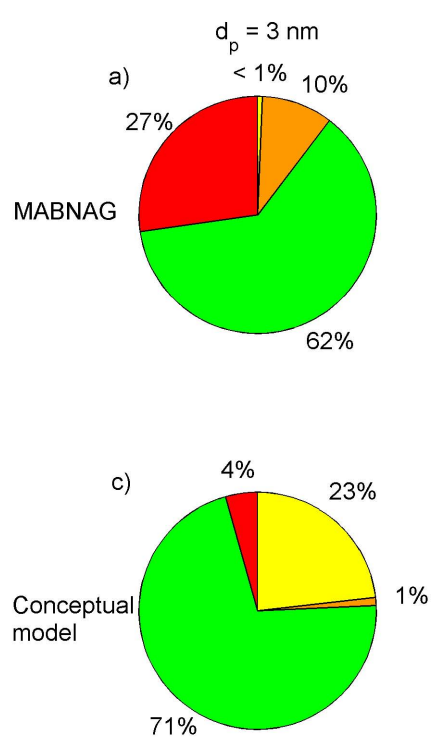

Sulfuric acid $\square$ Organic acid
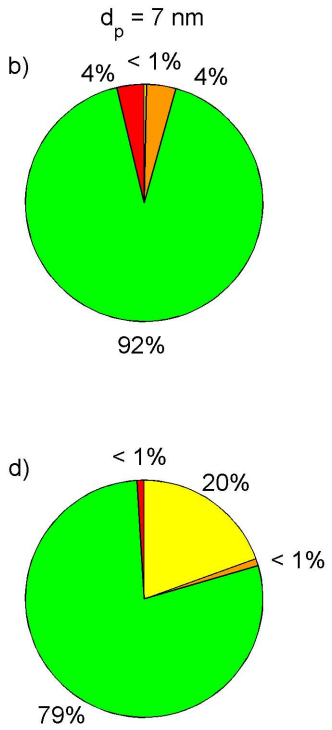

$92 \%$

Ammonia

Fig. 8. Dry mass fractions in the particle at $3 \mathrm{~nm}(\mathbf{a}, \mathbf{c})$ and $7 \mathrm{~nm}$ (b, d) predicted with MABNAG (a, b) and the conceptual growth model (c, d; Riipinen et al. 2012). Gas phase concentration of sulfuric acid, organic acid, ammonia and amine were $10^{6} \mathrm{~cm}^{-3}$, $3 \times 10^{8} \mathrm{~cm}^{-3}, 10^{10} \mathrm{~cm}^{-3}$ and $10^{8} \mathrm{~cm}^{-3}$, respectively, and $\mathrm{RH}$ was $40 \%$. Saturation vapour pressure of organic acid was set to $10^{-6} \mathrm{~Pa}$ and other properties of organic acid were as for organic acid 1 (Table 1).

for decreasing organic acid concentration by $50 \%$ but still achieving GR comparable to the measured values.

With the gas phase concentrations estimated based on the measurements, the model predicted that all the ammonia and amine was protonated in the particle phase (Fig. 9c). Most

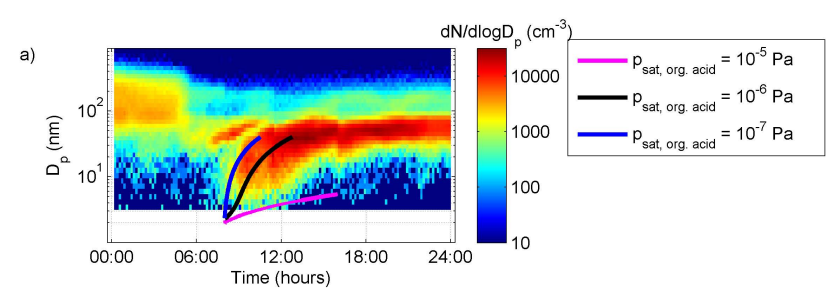

b)

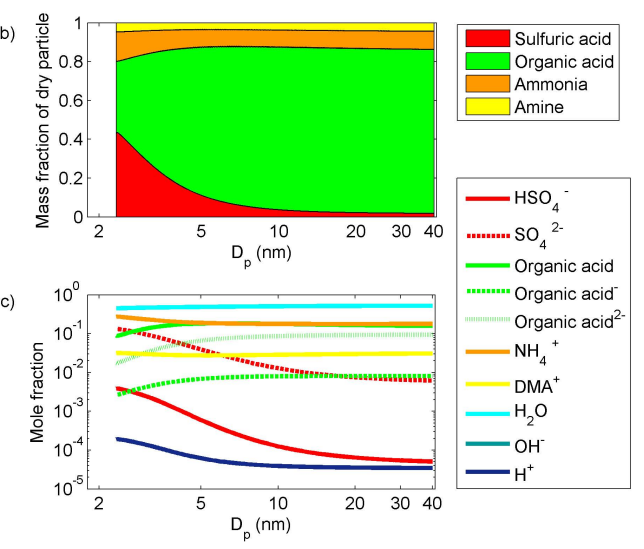

Fig. 9. (a) Particle size distribution measured on the case study day and particle size predicted with MABNAG using gas phase concentrations estimated based on measurements and base case properties for organic acid. Note that constant vapour concentrations were used in the model and the starting time for modelled particle growth is not specified in the model. Dry particle mass fractions (b) and mole fractions (c) are shown for the model run with $p_{\text {sat, Org. acid }}=10^{-6} \mathrm{~Pa}$.

of the sulfuric acid dissociated twice and was as $\mathrm{SO}_{4}^{2-}$ in the particles. Ratio between $\mathrm{HSO}_{4}^{-}$and $\mathrm{SO}_{4}^{2-}$ was rather constant during the growth. Most of the organic acid was in its non-dissociated form in the particle phase. The dissociated 
fraction of the organic acid increased during the particle growth from $18 \%$ at the beginning to $39 \%$ at $40 \mathrm{~nm}$. The dissociated fraction of the organic acid was dominated by the second dissociation product and only $2-3 \%$ of organic acid was as its first dissociation product.

\section{Conclusions}

The particle growth model MABNAG was developed and applied for studying atmospheric nanoparticle growth. MABNAG considers the condensation of mixtures of organic and inorganic vapours together with water, calculates the acidbase chemistry in the particle phase thermodynamically and takes into account both the size and composition dependence of equilibrium vapour pressures.

According to the model predictions for typical ambient conditions at Hyytiälä, only a small fraction of organic acid dissociated in the particle phase and, thus, a rather low $\left(10^{-6} \mathrm{~Pa}\right)$ saturation vapour pressure of organic acid was required for reaching realistic atmospheric nanoparticle growth rates, even though the acid dissociation was taken into account. It should be noted that here all the organic acids were grouped as one model compound. Therefore, the results suggest that on average the organic compounds should be less volatile than, e.g. malonic acid, and that there is likely some larger, stickier, organic compounds also condensing on the atmospheric nanoparticles. However, the possibility of simultaneous condensation of organic acids or other type of organic compounds with higher saturation vapour pressure is not excluded.

Short-chain organic acids have been observed to account for a large fraction of nanoparticle mass in the atmosphere (Smith et al., 2010). This would not be predicted in MABNAG since these compounds have even higher saturation vapour pressures than malonic acid. This suggests that there are other processes affecting the condensation of the organic acids in addition to salt formation or that the acidbase chemistry in the model does not capture the real system correctly. For instance, formation of organosulfates, amides, oligomerization and particle phase oxidation could produce low-volatility compounds in the particle but are not included in MABNAG. On the other hand, the small size-scale of nanoparticles affects the behaviour of the compounds due to which bulk-based thermodynamics might not capture all the properties right for nanoparticles.

Relative contributions of ammonia and amine to particle mass depended on their relative gas phase concentrations. For all the particle sizes, ammonia was the more important base when its gas phase concentration was one order of magnitude or more higher than the gas phase concentration of amine. Otherwise, amine was a more important base, which is in agreement with equilibrium calculations by Barsanti et al. (2009) and quantum chemistry calculations on nucleation by Kurtén et al. (2008). Mass-wise the bases seem to be more important for the smallest particles. In most conditions, condensation of ammonia and amine was driven by particle phase chemistry, mainly neutralization of sulfuric acid. For base-rich condition the partitioning of the bases between gas and particle phase was, however, driven by their high gas phase concentration.

Results from MABNAG for typical conditions at Hyytiälä suggest that salt formation has a minor role in the condensation of organic acids on the nanoparticles. However, only an order of magnitude increase in the gas phase concentration of either of the bases would make organic salt formation an important process for particle growth. Salt formation is also predicted to be more important at higher RH. For the condensation of sulfuric acid, ammonia and amine salt formation was predicted to be a crucial process since none of these three compounds existed in the particle phase in their neutral form. In total the salts were predicted to account for $50 \%, 13 \%$ and $11 \%$, respectively, of the mass of $3 \mathrm{~nm}, 7 \mathrm{~nm}$ and $20 \mathrm{~nm}$ particles in the typical gas phase concentrations at Hyytiälä. At elevated base concentrations salts accounted for more than $90 \%$ of the particle mass.

Our results indicate that acid-base chemistry seems not to be the limiting process for the growth of 3-20 nm particles in the boreal forest conditions, and the formation of organic salts is probably not enough to explain the observed very low volatility of the organics condensing on atmospheric nanoparticles. The situation changes considerably and very steeply, however, for base-rich conditions (ammonia concentration larger than $10^{10} \mathrm{~cm}^{-3}$ for amine concentrations larger than $10^{8} \mathrm{~cm}^{-3}$ ) where acid-base chemistry starts to dominate the organic vapour uptake. We believe that our results give a reasonable first estimate on the upper limit of possible contribution of salt formation to nanoparticle growth, as they rely on the state-of-the-art thermodynamics of an atmospherically relevant chemical mixture. To confirm the details of the acid-base chemistry of the atmospheric nanoparticle growth, however, further studies on, e.g. the thermodynamic properties of the atmospheric organic compounds and amines, the atmospheric concentrations of low-volatility organics and amines, along with studies investigating the applicability of thermodynamics for the smallest nanoparticles are needed. Measuring the evolution of nanoparticle composition during the growth is challenging, but as the experimental techniques on this area develop, such measurements will serve as an important comparison point in validating the growth model.

\section{Appendix A}

\section{Ambient conditions from measured data}

This appendix describes the measurements which were used for estimating the ambient conditions needed as inputs in MABNAG. The inputs required for MABNAG are the gas phase concentrations of all the condensing vapours, $\mathrm{RH}$ and 
temperature. In this study the data measured at Hyytiälä SMEAR II (Station for Measuring Ecosystem-Atmosphere Relations) research station, southern Finland, were used. Hyytiälä is a background site situated on the boreal forest zone. The surroundings of the station are dominated by Scots pine (Hari and Kulmala, 2005).

The base case values and range of values used in simulation sets 1-4 were estimated based on the typical values for the atmospheric parameters measured at Hyytiälä. The case study day 23 July 2010 was during an intensive measurement campaign at Hyytiälä (Williams et al., 2011) and there were measurements for most of the quantities required as input for MABNAG.

\section{A1 Sulfuric acid}

Typical sulfuric acid vapour concentrations were estimated based on Petäjä et al. (2009), where sulfuric acid concentrations were measured during spring and summer 2007. Base case value was taken to be the median daytime concentration of sulfuric acid on new particle formation event days $\left(1 \times 10^{6} \mathrm{~cm}^{-3}\right)$. The maximum measured sulfuric acid concentration was approximately $1 \times 10^{7} \mathrm{~cm}^{-3}$, which gave us the middle value for sulfuric acid concentration. The highest concentration in our study, $1 \times 10^{8} \mathrm{~cm}^{-3}$, is highly overestimating the sulfuric acid concentration for Hyytiälä and is included in our analysis to represent sulfuric rich environments, e.g. Atlanta (McMurry et al., 2005).

On the case study day, sulfuric acid concentration was measured with a chemical ionization mass spectrometer (CIMS; Eisele and Tanner, 1991; Petäjä et al., 2009). Sulfuric acid concentration varied between $1 \times 10^{6} \mathrm{~cm}^{-3}$ and $4 \times 10^{6} \mathrm{~cm}^{-3}$ during the time that the particles grew to reach $50 \mathrm{~nm}$, and the average concentration was $3 \times 10^{6} \mathrm{~cm}^{-3}$.

\section{A2 Organic acid}

Oxidized organic vapour concentrations are rarely measured and therefore condensable organic vapour concentrations could not be obtained directly from measurements. Estimate for organic acid concentration can be obtained from the concentration of oxidation products of monoterpenes. Rate of change of gas phase concentration of the oxidation products of monoterpenes ( $\left.C_{\text {monot. oxid. }}\right)$ can be estimated as (e.g. Dal Maso et al., 2005)

$$
\frac{\mathrm{d} C_{\text {monot.oxid. }}}{\mathrm{d} t}=Q-\mathrm{CS} \cdot C_{\text {monot.oxid. }} \text {, }
$$

where $Q$ is the sum of oxidation rates of monoterpenes by $\mathrm{OH}$ and $\mathrm{O}_{3}$ and $\mathrm{CS}$ is the condensation sink of oxidation products on particles. Equation (A1) assumes that the only loss for the oxidation products is condensation on particle, CS is same for all the oxidation products and equilibrium vapour pressures of the oxidation products are negligible compared to the ambient gas phase concentrations. Therefore, Eq. (A1) can be used only as an order of magnitude estimate. Assuming steady state, the concentration of oxidation products is

$$
C_{\text {monot.oxid. }}=\frac{Q}{\mathrm{CS}} \text {. }
$$

For order of magnitude estimation the CS of monoterpene oxidation products can be approximated with the CS of sulfuric acid, which is typically of the order of $10^{-3} \mathrm{~s}^{-1}$ at Hyytiälä (Dal Maso et al., 2005). Oxidation rate depends on the rate constants $\left(k_{\mathrm{OH}}, k_{\mathrm{O}_{3}}\right)$, gas phase concentration of oxidizing compounds $\mathrm{OH}$ and $\mathrm{O}_{3}\left(C_{\mathrm{OH}}, C_{\mathrm{O}_{3}}\right)$ and monoterpene concentration $\left(C_{\text {monot. }}\right)$ :

$Q=k_{\mathrm{OH}} C_{\mathrm{OH}} C_{\text {monot. }}+k_{\mathrm{O}_{3}} C_{\mathrm{O}_{3}} C_{\text {monot. }}$.

Rate constants calculated as weighted averages based on typical relative abundances of different monoterpenes at Hyytiälä are estimated to be $k_{\mathrm{OH}}=7.5 \times 10^{-11} \mathrm{~cm}^{3}$ molecules $^{-1} \mathrm{~s}^{-1}$ and $k_{\mathrm{O}_{3}}=$ $1.4 \times 10^{-17} \mathrm{~cm}^{3}$ molecules ${ }^{-1} \mathrm{~s}^{-1}$ (Yli-Juuti et al., 2011). $\mathrm{OH}$ concentrations of $3-6 \times 10^{5} \mathrm{~cm}^{-3}$ have been reported for nucleation and growth periods at Hyytiälä (Petäjä et al., 2009). Typical $\mathrm{O}_{3}$ concentrations are $6 \times 10^{11}$ $1 \times 10^{12} \mathrm{~cm}^{-3}$ on the particle formation days (Lyubovtseva et al., 2005). Daytime monoterpene mixing ratios at Hyytiälä during spring when new particle formation is most frequent are approximately $0.1 \mathrm{ppbv}$ and throughout the year stay mostly below $0.4 \mathrm{ppbv}$ (Lappalainen et al., 2009), which correspond to concentrations of $2.6 \times 10^{9} \mathrm{~cm}^{-3}$ and $1 \times 10^{10} \mathrm{~cm}^{-3}$, respectively. Based on these rate constants and concentrations, typical concentration of monoterpene oxidation products would be of the order of $10^{8} \mathrm{~cm}^{3}$ and maximum estimate would be $10^{9} \mathrm{~cm}^{-3}$. These were used as the base case and maximum values for the organic acid concentration. According to these calculations, organic acid concentration was approximately $5 \%$ of monoterpene concentration. The lower limit for organic acid concentration was taken to be $10^{7} \mathrm{~cm}^{-3}$ as concentrations of at least this order of magnitude are needed to explain the particle growth rates observed in the atmosphere.

For the case study day, monoterpene concentrations measured at Hyytiälä with proton transfer reaction mass spectrometer (PTR-MS) were used to estimate gas phase concentration of the organic acid. There was a measurement break with PTR-MS in the morning and the data was available only starting from 11:00. The median monoterpene concentration between 11:00 and 18:00 was $3.9 \times 10^{9} \mathrm{~cm}^{-3}$. This corresponds to organic acid concentration of approximately $2 \times 10^{8} \mathrm{~cm}^{-3}$ when $5 \%$ of monoterpenes are assumed to oxidize and form organic acid.

\section{A3 Ammonia}

Gas phase ammonia concentrations measured with MARGA (ten Brink et al., 2007; Makkonen et al., 2010) with 
one-hour time resolution at Hyytiälä during July 2010April 2011 where used for estimating typical concentrations. Median and 5th and 95th percentiles of daytime concentrations were $2.4 \times 10^{9} \mathrm{~cm}^{-3}, 5.5 \times 10^{8} \mathrm{~cm}^{-3}$, respectively, and $2.1 \times 10^{10} \mathrm{~cm}^{-3}$ while maximum concentration was $8.7 \times 10^{10} \mathrm{~cm}^{-3}$. Based on these, the base case value was taken to be $10^{9} \mathrm{~cm}^{-3}$ and the minimum and the maximum were chosen as $10^{8} \mathrm{~cm}^{-3}$ and $10^{11} \mathrm{~cm}^{-3}$. As $10^{11} \mathrm{~cm}^{-3}$ is rather extreme based on the measurements, also an intermediate value of $10^{10} \mathrm{~cm}^{-3}$ was used to represent high, but still reasonable, ammonia concentration.

On the case study day, there was a measurement break with MARGA in the morning and ammonia concentration data was available only starting from 13:00. In the afternoon, ammonia concentration had a decreasing trend and therefore the value at $13: 00,2 \times 10^{10} \mathrm{~cm}^{-3}$, was taken to represent the growth period.

\section{A4 Amine}

Gas phase amine concentrations measured during JuneAugust 2010 and May-October 2011 were used for estimating typical amine concentrations. The sampling period for these off-line analysis methods was 2-3 days during 2010 and 7 days during 2011. Samples were collected on acid impregnated filters through PTFE membrane filter. Extracts from filters were analysed using a high performance liquid chromatography electro spray ionisation ion trap mass spectrometer (Agilent 1100 Series LC/MSD Trap System). Sample collection and analytical procedure are described by Kieloaho et al. (2013). Concentrations of seven low molecular weight aliphatic amines were measured: trimethylamine, triethylamine, ethylamine, propylamine, butylamine, dimethylamine and diethylamine. During 2011 dimethylamine (DMA) and ethylamine (EA) were not separated in analysis, and the measured concentration represented the sum of these two amines. During 2010 DMA and EA were distinguished from each other in the analysis and on average DMA accounted for $10 \%$ of the total amine concentration. During 2010 there were leakages in the sampling system, causing the measured concentrations to be underestimates. Therefore, for estimating typical amine concentrations, measurements from 2011 were used. Median, minimum and maximum of the sum of the concentrations of the seven measured amines were $1.5 \times 10^{9} \mathrm{~cm}^{-3}, 7.8 \times 10^{8} \mathrm{~cm}^{-3}$ and $6.1 \times 10^{9} \mathrm{~cm}^{-3}$, respectively. This gave a conservative estimate of average sum of amine concentrations $10^{9} \mathrm{~cm}^{-3}$ and typical range of concentration $10^{8} \mathrm{~cm}^{-3}-10^{10} \mathrm{~cm}^{-3}$. It should be noted that all the amines were grouped in one compound in the model and these gas phase amine concentrations refer to the sum of the measured amines. Properties of DMA are used in the model for the amine although DMA accounted for only a fraction of the total measured amine concentration, which may have lead to overestimation of salt formation. Therefore, the model results are, from this per- spective, maximum estimates for salt formation. From the recent review on atmospheric amines by Ge et al. (2011a), the best comparison points for Hyytiälä are the rural and agricultural sites where concentration levels of low molecular weight aliphatic amines have been reported to be of the order of $10^{8}-10^{9} \mathrm{~cm}^{-3}$.

Sum of amine concentrations during the two sampling periods around the case study day 23 July 2010 were $8.8 \times 10^{7} \mathrm{~cm}^{-3}$ (21-23 July 2010) and $1.4 \times 10^{8} \mathrm{~cm}^{-3}(23-$ 26 July 2010). Due to the leakage in sampling these concentrations are likely to be underestimates, even by an order of magnitude, and, therefore, amine concentration of $10^{9} \mathrm{~cm}^{-3}$ was used in the model for the case study day.

\section{A5 Temperature and relative humidity}

During years 2003-2009 average temperature during new particle formation events was $281.5 \mathrm{~K}$ and minimum and maximum were $257.0 \mathrm{~K}$ and $294.7 \mathrm{~K}$, respectively. It is worth noting that temperature dependence of saturation vapour pressures of organic compounds was not included in the model. Therefore, the temperature dependence was not studied, and in all simulations temperature was set to $283.15 \mathrm{~K}$.

The average relative humidity during nanoparticle growth was $43 \%$ with 5 th and 95 th percentiles of $26 \%$ and $74 \%$, respectively, and with maximum value reaching $92 \%$.

Acknowledgements. This research was supported by the Academy of Finland Centre of Excellence program (project no. 1118615), Doctoral Programme in Atmospheric Composition and Climate Change: From Molecular Processes to Global Observations and Models (project no. 129663), Vetenskapsrådet (project no. 2011-5120), European Research Council grant ATMOGAIN (no. 278277), and US DOE grant (no. DE-SC0006861). Authors would like to thank S. Clegg for providing access to E-AIM and for the discussions regarding the use of E-AIM.

Edited by: K. Carslaw

\section{References}

Aalto, P., Hämeri, K., Becker, E., Weber, R., Salm, J., Mäkelä, J. M., Hoell, C., O’Dowd, C. D., Karlsson, H., Hansson, H.-C., Väkevä, M., Koponen, I. K., Buzorius, G., and Kulmala, M.: Physical characterization of aerosol particles during nucleation events, Tellus, 53, 344-358, 2001.

Allan, J. D., Alfarra, M. R., Bower, K. N., Coe, H., Jayne, J. T., Worsnop, D. R., Aalto, P. P., Kulmala, M., Hyötyläinen, T., Cavalli, F., and Laaksonen, A.: Size and composition measurements of background aerosol and new particle growth in a Finnish forest during QUEST 2 using an Aerodyne Aerosol Mass Spectrometer, Atmos. Chem. Phys., 6, 315-327, doi:10.5194/acp-6-315-2006, 2006.

Balslev, K. and Abildskov, J.: UNIFAC parameters for four new groups, Ind. Eng. Chem. Res., 41, 2047-2057, 2002. 
Barsanti, K. C., McMurry, P. H., and Smith, J. N.: The potential contribution of organic salts to new particle growth, Atmos. Chem. Phys., 9, 2949-2957, doi:10.5194/acp-9-2949-2009, 2009.

Berndt, T., Stratmann, F., Sipilä, M., Vanhanen, J., Petäjä, T., Mikkilä, J., Grüner, A., Spindler, G., Lee Mauldin III, R., Curtius, J., Kulmala, M., and Heintzenberg, J.: Laboratory study on new particle formation from the reaction $\mathrm{OH}+\mathrm{SO}_{2}$ : influence of experimental conditions, $\mathrm{H}_{2} \mathrm{O}$ vapour, $\mathrm{NH}_{3}$ and the amine tert-butylamine on the overall process, Atmos. Chem. Phys., 10, 7101-7116, doi:10.5194/acp-10-7101-2010, 2010.

Birmili, W., Berresheim, H., Plass-Dülmer, C., Elste, T., Gilge, S., Wiedensohler, A., and Uhrner, U.: The Hohenpeissenberg aerosol formation experiment (HAFEX): a long-term study including size-resolved aerosol, $\mathrm{H}_{2} \mathrm{SO}_{4}, \mathrm{OH}$, and monoterpenes measurements, Atmos. Chem. Phys., 3, 361-376, doi:10.5194/acp-3-361-2003, 2003.

Boy, M., Kulmala, M., Ruuskanen, T. M., Pihlatie, M., Reissell, A., Aalto, P. P., Keronen, P., Dal Maso, M., Hellen, H., Hakola, H., Jansson, R., Hanke, M., and Arnold, F.: Sulphuric acid closure and contribution to nucleation mode particle growth, Atmos. Chem. Phys., 5, 863-878, doi:10.5194/acp-5-863-2005, 2005.

Bzdek, B. R., Zordan, C. A., Pennington, M. R., Luther III, G. W., and Johnston, M. V.: Quantitative assessment of the sulfuric acid contribution to new particle growth, Environ. Sci. Technol., 46, 4365-4373, 2012.

Clegg, S. L. and Brimblecombe, P.: Application of a multicomponent thermodynamic model to activities and thermal properties of $0-40 \mathrm{~mol} \mathrm{~kg}^{-1}$ aqueous sulphuric acid from < 200 to $328 \mathrm{~K}$, J. Chem. Eng. Data, 40, 43-64, 1995.

Clegg, S. L. and Seinfeld, J. H.: Thermodynamic models of aqueous solutions containing inorganic electrolytes and dicarboxylic acids at $298.15 \mathrm{~K}$. 1. The acids as non-dissociating components, J. Phys. Chem. A, 110, 5692-5717, 2006a.

Clegg, S. L. and Seinfeld, J. H.: Thermodynamic models of aqueous solutions containing inorganic electrolytes and dicarboxylic acids at 298.15 K. 2. Systems including dissociation equilibria, J. Phys. Chem. A, 110, 5718-5734, 2006 b.

Clegg, S. L., Pitzer, K. S., and Brimblecombe, P.: Thermodynamics of multicomponent, miscible, ionic solutions. 2. Mixtures including unsymmetrical electrolytes, J. Phys. Chem., 96, 9470-9479, 1992.

Clegg, S. L., Seinfeld, J. H., and Brimblecombe, P.: Thermodynamic modelling of aqueous aerosols containing electrolytes and dissolved organic compounds, J. Aerosol Sci., 32, 713-738, 2001.

Dal Maso, M., Kulmala, M., Riipinen, I., Wagner, R., Hussein, T., Aalto, P. P., and Lehtinen, K. E. J.: Formation and growth of fresh atmospheric aerosols: eight years of aerosol size distribution data from SMEAR II, Hyytiälä, Finland, Boreal Environ. Res., 10, 323-336, 2005.

DePalma, J. W., Bzdek, B. R., Doren, D. J., and Johnston, M. V.: Structure and energetics of nanometer size clusters of sulfuric acid with ammonia and dimethylamine, J. Phys. Chem. A, 116, 1030-1040, 2012.

Donahue, N. M., Trump, E. R., Pierce, J. R., and Riipinen, I.: Theoretical constraints on pure vapor-pressure driven condensation of organics to ultrafine particles, Geophys. Res. Lett., 38, L16801, doi:10.1029/2011GL048115, 2011.
Eisele, F. L. and Tanner, D. J.: Ion-assisted tropospheric OH measurements, J. Geophys. Res., 96, 9295-9308, 1991.

Fiedler, V., Dal Maso, M., Boy, M., Aufmhoff, H., Hoffmann, J., Schuck, T., Birmili, W., Hanke, M., Uecker, J., Arnold, F., and Kulmala, M.: The contribution of sulphuric acid to atmospheric particle formation and growth: a comparison between boundary layers in Northern and Central Europe, Atmos. Chem. Phys., 5, 1773-1785, doi:10.5194/acp-5-1773-2005, 2005.

Fredenslund A., Jones, R. L., and Prausnitz, J. M.: Groupcontribution estimation of activity coefficinets in nonideal liquidmixtures, Aiche J., 21, 1086-1099, 1975.

Fuchs N. A. and Sutugin, A. G.: Highly dispersed aerosols, Ann Arbor Science Publishers, London, 1970.

Ge, X., Wexler, A. S., and Clegg, S.: Atmospheric amines - Part I. A review, Atmos. Environ., 45, 524-546, $2011 \mathrm{a}$.

Ge, X., Wexler, A. S., and Clegg, S.: Atmospheric amines - Part II, Thermodynamic properties and gas/particle partitioning, Atmos. Environ., 45, 561-577, 2011b.

Goldstein, A. H. and Galbally, I. E.: Known and unexplored organic constituents in the Earth's atmosphere, Environ. Sci. Technol., 41, 1514-1521, 2007.

Hamed, A., Korhonen, H., Sihto, S.-L., Joutsensaari, J., Järvinen, H., Petäjä, T., Arnold, F., Nieminen, T., Kulmala, M., Smith, J. N., Lehtinen, K. E. J., and Laaksonen, A.: The role of relative humidity in continental new particle formation, J. Geophys. Res., 116, D03202, doi:10.1029/2010JD014186, 2011.

Hansen, H. K., Rasmussen, P., Fredenslund, A., Schiller, M., and Gmehling, J.: Vapor-Liquid Equilibria by UNIFAC Group Contribution. 5. Revision and Extension, Ind. Eng. Chem. Res., 30, 2352-2355, 1991

Hari, P. and Kulamala, M.: Station for Measuring EcosystemAtmosphere Relations (SMEAR II), Boreal Environ. Res., 10, 315-322, 2005.

Hirsikko, A., Laakso, L., Hõrrak, U., Aalto, P. P., Kerminen, V.M., and Kulmala, M.: Annual and size dependent variation of growth rates and ion concentrations in boreal forest, Boreal Environ. Res., 10, 357-369, 2005.

Jimenez, J. L., Canagaratna, M. R., Donahue, N. M., Prevot, A. S. H., Zhang, Q., Kroll, J. H., DeCarlo, P. F., Allan, J. D., Coe, H., Ng, N. L., Aiken, A. C., Docherty, K. S., Ulbrich, I. M., Grieshop, A. P., Robinson, A. L., Duplissy, J., Smith, J. D., Wilson, K. R., Lanz, V. A., Hueglin, C., Sun, Y. L., Tian, J., Laaksonen, A., Raatikainen, T., Rautiainen, J., Vaattovaara, P., Ehn, M., Kulmala, M., Tomlinson, J. M., Collins, D. R., Cubison, M. J., Dunlea, E. J., Huffman, J. A., Onasch, T. B., Alfarra, M. R., Williams, P. I., Bower, K., Kondo, Y., Schneider, J., Drewnick, F., Borrmann, S., Weimer, S., Demerjian, K., Salcedo, D., Cottrell, L., Griffin, R., Takami, A., Miyoshi, T., Hatakeyama, S., Shimono, A., Sun, J. Y., Zhang, Y. M., Dzepina, K., Kimmel, J. R., Sueper, D., Jayne, J. T., Herndon, S. C., Trimborn, A. M., Williams, L. R., Wood, E. C., Middlebrook, A. M., Kolb, C. E., Baltensperger, U., and Worsnop, D. R.: Evolution of organic aerosols in the atmosphere, Science, 326, 1525-1529, 2009.

Kerminen, V.-M., Lehtinen, K. E. J., Anttila, T., and Kulmala, M.: Dynamics of atmospheric nucleation mode particles: a timescale analysis, Tellus, 56, 135-146, 2004.

Kieloaho, A.-J., Hellén, H., Hakola, H., Manninen, H. E., Nieminen, T., Kulmala, M., and Pihlatie, M.: Gas-phase alkylamines 
in a boreal Scots pine forest air, Atmos. Environ., 80, 369-377, 2013.

Kirkby, J., Curtius, J., Almeida, J., Dunne, E., Duplissy, J., Ehrhart, S., Franchin, A., Gagne, S., Ickes, L., Kurten, A., Kupc, A., Metzger, A., Riccobono, F., Rondo, L., Schobesberger, S., Tsagkogeorgas, G., Wimmer, D., Amorim, A., Bianchi, F., Breitenlechner, M., David, A., Dommen, J., Downard, A., Ehn, M., Flagan, R. C., Haider, S., Hansel, A., Hauser, D., Jud, W., Junninen, H., Kreissl, F., Kvashin, A., Laaksonen, A., Lehtipalo, K., Lima, J., Lovejoy, E. R., Makhmutov, V., Mathot, S., Mikkila, J., Minginette, P., Mogo, S., Nieminen, T., Onnela, A., Pereira, P., Petäjä, T., Schnitzhofer, R., Seinfeld, J. H., Sipilä, M., Stozhkov, Y., Stratmann, F., Tome, A., Vanhanen, J., Viisanen, Y., Vrtala, A., Wagner, P. E., Walther, H., Weingartner, E., Wex, H., Winkler, P. M., Carslaw, K. S., Worsnop, D. R., Baltensperger, U., and Kulmala, M.: Role of sulphuric acid, ammonia and galactic cosmic rays in atmospheric aerosol nucleation, Nature, 476, 429-433, 2011.

Kroll, J. H. and Seinfeld, J. H.: Chemistry of secondary organic aerosol: Formation and evolution of low-volatility organics in the atmosphere, Atmos. Environ., 42, 3593-3624, 2008.

Kuang, C., McMurry, P. H., McCormick, A. V., and Eisele, F. L.: Dependence of nucleation rates on sulfuric acid vapor concentration in diverse atmospheric locations, J. Geophys. Res., 113, D10209, doi:10.1029/2007JD009253, 2008.

Kuang, C., Chen, M., Zhao, J., Smith, J., McMurry, P. H., and Wang, J.: Size and time-resolved growth rate measurements of 1 to $5 \mathrm{~nm}$ freshly formed atmospheric nuclei, Atmos. Chem. Phys., 12, 3573-3589, doi:10.5194/acp-12-3573-2012, 2012.

Kulmala, M., Lehtinen, K. E. J., and Laaksonen, A.: Cluster activation theory as an explanation of the linear dependence between formation rate of $3 \mathrm{~nm}$ particles and sulphuric acid concentration, Atmos. Chem. Phys., 6, 787-793, doi:10.5194/acp-6-787-2006, 2006.

Kurtén, T., Loukonen, V., Vehkamäki, H., and Kulmala, M.: Amines are likely to enhance neutral and ion-induced sulfuric acid-water nucleation in the atmosphere more effectively than ammonia, Atmos. Chem. Phys., 8, 4095-4103, doi:10.5194/acp-8-4095-2008, 2008.

Laitinen, T., Ehn, M. Junninen, H., Ruiz-Jimenez, J., Parshintsev, J., Hartonen, K., Riekkola, M.-L., Worsnop, D. R., and Kulmala, M.: Characterization of organic compounds in 10- to $50-\mathrm{nm}$ aerosol particles in boreal forest with laser desorptionionization aerosol mass spectrometer and comparison with other techniques, Atmos. Environ., 45, 3711-3719, 2011.

Lappalainen, H. K., Sevanto, S., Bäck, J., Ruuskanen, T. M., Kolari, P., Taipale, R., Rinne, J., Kulmala, M., and Hari, P.: Daytime concentrations of biogenic volatile organic compounds in a boreal forest canopy and their relation to environmental and biological factors, Atmos. Chem. Phys., 9, 5447-5459, doi:10.5194/acp-9-5447-2009, 2009.

Lehtinen, K. E. J. and Kulmala, M.: A model for particle formation and growth in the atmosphere with molecular resolution in size, Atmos. Chem. Phys., 3, 251-257, doi:10.5194/acp-3-251-2003, 2003.

Lide, D. R. (Ed.): CRC Handbook of Chemistry and Physics, 90th Edn., CRC Press, Boca Raton, Florida, 2009.

Limbeck, A., Kulmala, M., and Puxbaum, H.: Secondary organic aerosol formation in the atmosphere via heterogeneous reaction of gaseous isoprene on acidic particles, Geophys. Res. Lett., 30, 1996, doi:10.10.1029/2003GL017738, 2003.

Lyubovtseva, Y. S., Sogacheva, L., Dal Maso, M., Bonn, B., Keronen, P., and Kulmala, M.: Seasonal variations of trace gases, meteorological parameters, and formation of aerosols in boreal forest, Boreal Environ. Res., 10, 493-510, 2005.

Makkonen, U., Hellén, H., Anttila, P., and Ferm, M.: Size distribution and chemical composition of airborne particles in southeastern Finland during different seasons and wildfire episodes in 2006, Sci. Total Environ., 408, 644-651, 2010.

McMurry, P. H., Fink, M., Sakurai, H., Stolzenburg, M. R., Mauldin, R. L. III, Smith, J., Eisele, F., Moore, K., Sjostedt, S., Tanner, D., Huey, L. G., Nowak, J. B., Edgerton, E., and Voisin, D.: A criterion for new particle formation in the sulfur-rich Atlanta atmosphere, J. Geophys. Res., 110, D22S02, doi:10.1029/2005JD005901, 2005.

Merikanto, J., Spracklen, D. V., Mann, G. W., Pickering, S. J., and Carslaw, K. S.: Impact of nucleation on global CCN, Atmos. Chem. Phys., 9, 8601-8616, doi:10.5194/acp-9-8601-2009, 2009.

Mirme, A., Tamm, E., Mordas, G., Vana, M., Uin, J., Mirme, S., Bernotas, T., Laakso, L., Hirsikko, A., and Kulmala, M.: A widerange multi-channel Air Ion Spectrometer, Boreal Environ. Res., 12, 247-264, 2007.

Murphy, S. M., Sorooshian, A., Kroll, J. H., Ng, N. L., Chhabra, P., Tong, C., Surratt, J. D., Knipping, E., Flagan, R. C., and Seinfeld, J. H.: Secondary aerosol formation from atmospheric reactions of aliphatic amines, Atmos. Chem. Phys., 7, 2313-2337, doi:10.5194/acp-7-2313-2007, 2007.

O’Dowd, C. D., Aalto, P., Hämeri, K., Kulmala, M., and Hoffmann T.: Aerosol formation: Atmospheric particles from organic vapors, Nature, 416, 497-498, 2002.

Ortega, I. K., Kurtén, T., Vehkamäki, H., and Kulmala, M.: The role of ammonia in sulfuric acid ion induced nucleation, Atmos. Chem. Phys., 8, 2859-2867, doi:10.5194/acp-8-2859-2008, 2008.

Ortega, I. K., Kupiainen, O., Kurtén, T., Olenius, T., Wilkman, O., McGrath, M. J., Loukonen, V., and Vehkamäki, H.: From quantum chemical formation free energies to evaporation rates, Atmos. Chem. Phys., 12, 225-235, doi:10.5194/acp-12-225-2012, 2012.

Petäjä, T., Mauldin III, R. L., Kosciuch, E., McGrath, J., Nieminen, T., Paasonen, P., Boy, M., Adamov, A., Kotiaho, T., and Kulmala, M.: Sulfuric acid and $\mathrm{OH}$ concentrations in a boreal forest site, Atmos. Chem. Phys., 9, 7435-7448, doi:10.5194/acp9-7435-2009, 2009.

Pierce, J. R. and Adams, P. J.: Efficiency of cloud condensation nuclei formation from ultrafine particles, Atmos. Chem. Phys., 7, 1367-1379, doi:10.5194/acp-7-1367-2007, 2007.

Pierce, J. R., Riipinen, I., Kulmala, M., Ehn, M., Petäjä, T., Junninen, H., Worsnop, D. R., and Donahue, N. M.: Quantification of the volatility of secondary organic compounds in ultrafine particles during nucleation events, Atmos. Chem. Phys., 11, 90199036, doi:10.5194/acp-11-9019-2011, 2011.

Poling, B. E., Prausnitz, J. M., and O'Connell, J. P.: Properties of gases and liquids, 5th Edn., McGraw-Hill, New York, 2001.

Pope, F. D., Tong, H.-J., Dennis-Smither, B. J., Griffiths, P. T., Clegg, S. L., Reid, J. P., and Cox, A. A.: Studies of single aerosol particles containing malonic acid, glutaric acid, and their mix- 
tures with sodium chloride. II, Liquid-state vapor pressures of the acids, J. Phys. Chem. A., 114, 10156-10165, 2010.

Qiu, C. and Zhang, R.: Multiphase chemistry of atmospheric amines, Phys. Chem. Chem. Phys., 15, 5738-5752, 2013.

Riipinen, I., Manninen, H. E., Yli-Juuti, T., Boy, M., Sipilä, M., Ehn, M., Junninen, H., Petäjä, T., and Kulmala, M.: Applying the Condensation Particle Counter Battery (CPCB) to study the water-affinity of freshly-formed 2-9 nm particles in boreal forest, Atmos. Chem. Phys., 9, 3317-3330, doi:10.5194/acp-9-33172009, 2009.

Riipinen, I., Pierce, J. R., Donahue, N. M., and Pandis, S. N.: Equilibration time scales of organic aerosol inside thermodenuders: Evaporation kinetics versus thermodynamics, Atmos. Environ., 44, 597-607, 2010.

Riipinen, I., Pierce, J. R., Yli-Juuti, T., Nieminen, T., Häkkinen, S., Ehn, M., Junninen, H., Lehtipalo, K., Petäjä, T., Slowik, J., Chang, R., Shantz, N. C., Abbatt, J., Leaitch, W. R., Kerminen, V.-M., Worsnop, D. R., Pandis, S. N., Donahue, N. M., and Kulmala, M.: Organic condensation: a vital link connecting aerosol formation to cloud condensation nuclei $(\mathrm{CCN})$ concentrations, Atmos. Chem. Phys., 11, 3865-3878, doi:10.5194/acp-11-38652011, 2011.

Riipinen, I., Yli-Juuti, T., Pierce, J. R., Petäjä, T., Worsnop, D. R., Kulmala, M., and Donahue, N. M.: The contribution of organics to atmospheric nanoparticle growth, Nat. Geosci., 5, 453-458, 2012.

Saleh, R., Shihadeh, A., and Khlystov, A.: On transport phenomena and equilibration time scales in thermodenuders, Atmos. Meas. Tech., 4, 571-581, doi:10.5194/amt-4-571-2011, 2011.

Seinfeld, J. H. and Pandis, S. N.: Atmospheric chemistry and physics: From air pollution to climate change, 2nd Edn., John Wiley \& Sons, Inc., New Jersey, 2006.

Sipilä, M., Berndt, T., Petäjä, T., Brus, D., Vanhanen, J., Stratmann, F., Patokoski, J., Mauldin III, R. L., Hyvärinen, A.-P., Lihavainen, H., and Kulmala, M.: The role of sulfuric acid in atmospheric nucleation, Science, 327, 1243-1246, 2010.

Smith, J. N., Dunn, M. J., VanReken, T. M., Iida, K., Stolzenburg, M. R., McMurry, P. H., and Huey, L. G.: Chemical composition of atmospheric nanoparticles formed from nucleation in Tecamac, Mexico: Evidence for an important role for organic species in nanoparticle growth, Geophys. Res. Lett., 35, L04808, doi:10.1029/2007GL032523, 2008.

Smith, J. N., Barsanti, K. C., Friedli, H. R., Ehn, M., Kulmala, M., Collins, D. R., Scheckman, J. H., Williams, B. J., and McMurry, P. H.: Observations of aminium salts in atmospheric nanoparticles and possible climatic implications, Proc. Natl. Acad. Sci., 107, 6634-6639, 2010.

Stolzenburg, M. R., McMurry, P. H., Sakurai, H., Smith, J. N., Mauldin III, R. L., Eisele, F. L., and Clement, C. F.: Growth rates of freshly nucleated atmospheric particles in Atlanta, J. Geophys. Res., 110, D22S05, doi:10.1029/2005JD005935, 2005.
Tammet, H.: Continuous scanning of the mobility and size distribution of charged cluster and nanometer particles in atmospheric air and the Balanced Scanning Mobility Analyzer BSMA, Atmos. Res., 82, 523-535, 2006.

ten Brink, H., Otjes, R., Jongejan, P., and Slanina, S.: An instrument for semi-continuous monitoring of the size-distribution of nitrate, ammonium, sulphate and chloride aerosol, Atmos. Environ., 41, 2768-2779, 2007.

Weber, R. J., McMurry, P. H., Eisele, F. L., and Tanner, D. J.: Measurement of expected nucleation precursor species and 3-500 nm diameter particles at Mauna Loa observatory, Hawaii, J. Atmos. Sci., 52, 2242-2257, 1995.

Wexler, A. S. and Clegg, S. L.: Atmospheric aerosol models for systems including the ions $\mathrm{H}^{+}, \mathrm{NH}_{4}^{+}, \mathrm{Na}^{+}, \mathrm{SO}_{4}^{2-}$, $\mathrm{NO}_{3}^{-}, \mathrm{Cl}^{-}, \mathrm{Br}^{-}$and $\mathrm{H}_{2} \mathrm{O}$, J. Geophys. Res., 107, 4207, doi:10.1029/2001JD000451, 2002.

Williams, J., Crowley, J., Fischer, H., Harder, H., Martinez, M., Petäjä, T., Rinne, J., Bäck, J., Boy, M., Dal Maso, M., Hakala, J., Kajos, M., Keronen, P., Rantala, P., Aalto, J., Aaltonen, H., Paatero, J., Vesala, T., Hakola, H., Levula, J., Pohja, T., Herrmann, F., Auld, J., Mesarchaki, E., Song, W., Yassaa, N., Nölscher, A., Johnson, A. M., Custer, T., Sinha, V., Thieser, J., Pouvesle, N., Taraborrelli, D., Tang, M. J., Bozem, H., Hosaynali-Beygi, Z., Axinte, R., Oswald, R., Novelli, A., Kubistin, D., Hens, K., Javed, U., Trawny, K., Breitenberger, C. Hidalgo, P. J., Ebben, C. J., Geiger, F. M., Corrigan, A. L., Russell, L. M., Ouwersloot, H. G., Vilà-Guerau de Arellano, J., Ganzeveld, L., Vogel, A., Beck, M., Bayerle, A., Kampf, C. J., Bertelmann, M., Köllner, F., Hoffmann, T., Valverde, J., González, D., Riekkola, M.-L., Kulmala, M., and Lelieveld, J.: The summertime Boreal forest field measurement intensive (HUMPPA-COPEC-2010): an overview of meteorological and chemical influences, Atmos. Chem. Phys., 11, 10599-10618, doi:10.5194/acp-11-10599-2011, 2011.

Wittig, R., Lohmann, J., and Gmehling, J.: Vapor-Liquid Equilibria by UNIFAC Group Contribution. 6. Revision and Extension, Ind. Eng. Chem. Res., 42, 183-188, 2003.

Yli-Juuti, T., Nieminen, T., Hirsikko, A., Aalto, P. P., Asmi, E., Hõrrak, U., Manninen, H. E., Patokoski, J., Dal Maso, M., Petäjä, T., Rinne, J., Kulmala, M., and Riipinen, I.: Growth rates of nucleation mode particles in Hyytiälä during 20032009: variation with particle size, season, data analysis method and ambient conditions, Atmos. Chem. Phys., 11, 12865-12886, doi:10.5194/acp-11-12865-2011, 2011.

Zhang, R., Khalizov, A., Wang, L., Hu, M., and Xu, W.: Nucleation and growth of nanoparticles in the atmosphere, Chem. Rev., 112, 1957-2011, 2012. 